\title{
Article
}

\section{Uveitis as an Open Window to Systemic Inflammatory Diseases}

\author{
Thomas El Jammal $^{1}$, Olivier Loria ${ }^{2,3}$, Yvan Jamilloux ${ }^{1}$, Mathieu Gerfaud-Valentin ${ }^{1} \mathbb{D}$, Laurent Kodjikian ${ }^{2,3}$ (D) and \\ Pascal Sève $1,4,5, *$ (i)
}

1 Department of Internal Medicine, Hôpital de la Croix-Rousse, Université Claude Bernard Lyon I, 69004 Lyon, France; thomas_3901@hotmail.fr (T.E.J.); yvan.jamilloux@chu-lyon.fr (Y.J.); mathieu.gerfaud-valentin@chu-lyon.fr (M.G.-V.)

2 Department of Ophthalmology, Hôpital de la Croix-Rousse, Université Claude Bernard Lyon I, 69004 Lyon, France; olivier.loria@chu-lyon.fr (O.L.); laurent.kodjikian@chu-lyon.fr (L.K.)

3 Laboratoire UMR-CNRS 5510 Matéis, 69004 Villeurbane, France

4 IMER Department, Hospices Civils de Lyon, 69424 Lyon, France

5 Department of Formation and Research in Human Biology, Université Claude Bernard Lyon 1, HESPER EA 7425, 69008 Lyon, France

* Correspondence: pascal.seve@chu-lyon.fr; Tel.: +33-426-732-630; Fax: +33-426-732-637

Citation: El Jammal, T.; Loria, O.; Jamilloux, Y.; Gerfaud-Valentin, M.; Kodjikian, L.; Sève, P. Uveitis as an Open Window to Systemic Inflammatory Diseases. J. Clin. Med. 2021, 10, 281. https://doi.org/ $10.3390 / j \mathrm{~cm} 10020281$

Received: 11 November 2020 Accepted: 11 January 2021 Published: 14 January 2021

Publisher's Note: MDPI stays neutral with regard to jurisdictional clai$\mathrm{ms}$ in published maps and institutional affiliations.

Copyright: $(\odot 2021$ by the authors. Licensee MDPI, Basel, Switzerland. This article is an open access article distributed under the terms and conditions of the Creative Commons Attribution (CC BY) license (https:// creativecommons.org/licenses/by/ $4.0 /)$.

\begin{abstract}
Spondyloarthritis (Spa), Behçet's disease (BD) and sarcoidosis are major systemic inflammatory diseases worldwide. They are all multisystem pathologies and share a possible ocular involvement, especially uveitis. We hereby describe selected cases who were referred by ophthalmologists to our internal medicine department for unexplained uveitis. Physical examination and/or the use of laboratory and imaging investigations allowed to make a diagnosis of a systemic inflammatory disease in a large proportion of patients. In our tertiary referral center, 75 patients have been diagnosed with Spa $(n=20)$, BD $(n=9)$, or sarcoidosis $(n=46)$ in the last two years. There was a significant delay in the diagnosis of Spa-associated uveitis. Screening strategies using Human Leukocyte Antigen (HLA)-B27 determination and sacroiliac magnetic resonance imaging in patients suffering from chronic low back pain and/or psoriasis helped in the diagnosis. BD's uveitis affects young people from both sexes and all origins and usually presents with panuveitis and retinal vasculitis. The high proportion of sarcoidosis in our population is explained by the use of chest computed tomography (CT) and 18F-fluorodeoxyglucose positron emission tomography CT that helped to identify smaller hilar or mediastinal involvement and allowed to further investigate those patients, especially in the elderly. Our results confirm how in these sight- and potentially life-threatening diseases a prompt diagnosis is mandatory and benefits from a multidisciplinary approach.
\end{abstract}

Keywords: uveitis; sarcoidosis; HLA-B27 associated uveitis; spondyloarthritis; Behçet's disease

\section{Introduction}

Uveitis is defined as the inflammation of the iris, ciliary body, vitreous, retina, or choroid. Its incidence is $10.5-52 / 100,000$ person-years and the prevalence is 38-284/100,000 persons [1-3]. A study of medical insurance claims for 4 million individuals in the USA reported a prevalence of 133/100,000 persons, including a predominance of non-infectious uveitis (90.7\%), and anterior uveitis (AU, 80\%) [4]. A more recent study, in South Korea, among a national cohort of approximately 1,000,000 Korean residents, found a prevalence of uveitis, AU and non-AU of 17.3, 15.0, and 2.3 per 10,000 persons, respectively [3].

Uveitis is responsible for $5 \%$ of legal blindness cases (central visual acuity of $1 / 10$ or less in the better eye), mainly due to macular edema, ocular hypertension, or retinal ischemia [5].

Approximately 80 causes of uveitis have been described and these can be classified into five groups including pure ophthalmological entities, infectious [6] and inflammatory diseases, masquerade syndromes, and drug-induced (Table 1). Epidemiology varies according to genetic and ethnic factors (e.g., Human Leukocyte Antigen (HLA)-B27, sarcoidosis, etc.), environmental factors (e.g., tuberculosis in endemic countries), the definition of the 
disease (e.g., sarcoidosis), the inclusion of certain ophthalmologic entities in the group of idiopathic uveitis (e.g., pars planitis), the paraclinical investigations performed (e.g., nuclear imaging) and the method of patient recruitment (e.g., tertiary centers). This explains the great heterogeneity of the studies reported in the literature. The main etiologies (mostly reported from tertiary centers) are Vogt-Koyanagi-Harada disease (VKH) and sarcoidosis in Japan [7], VKH and Behçet's disease (BD) in China [8], BD in Turkey [9], HLA-B27-associated uveitis in Australia [10], herpesvirus in North Africa [11] and Thailand [12], tuberculosis in India [13], toxoplasmosis in South America [14], and infections (presumed tuberculosis, followed by cytomegalovirus infection and herpesvirus infection) in Singapore [15]. In Western countries, approximately a quarter of cases are related to ophthalmologic entities, a quarter to systemic diseases meeting consensual diagnostic criteria, a quarter to suspected systemic diseases, and a quarter to unexplained causes [16]. Uveitis of unexplained origin, also known as idiopathic uveitis, accounts for $23 \%$ to $44 \%$ of cases according to recent studies in the West and Japan $[10,17,18]$.

In the last twenty years alone, ten studies have been carried out on the distribution, clinical patterns, and etiologies of uveitis [18-20], mostly in ophthalmological centers, in Western Europe. As shown in Table 2, three systemic diseases are particularly prevalent: HLA-B27- and spondyloarthropathy (Spa)-associated uveitis, BD, and sarcoidosis.

In this study, our attention will focus on these entities.

Table 1. Main causes of uveitis in adults (From Sève et al., Autoimmun. Rev., 2017). The most common causes (>0.5\%) reported in most recent European series are indicated in bold type [21-29].

Etiology
Bacterial: syphilis, tuberculosis, Lyme disease, cat-scratch disease, rickettsiosis, leptospirosis,
brucellosis, Whipple's disease [30], chlamydiosis, tularemia, post-streptococcal [31]
Parasitic: toxoplasmosis, toxocariasis, onchocerciasis, cysticercosisViral: herpes simplex viruses 1
and 2, CMV, HTLV-1, Dengue virus, Ebola virus, Zika virus, West-Nile virus, Rift valley fever virus,
chikungunya virus, coronaviruses [32]
Fungal: candidiasis, histoplasmosis, aspergillosis, cryptococosis

\section{HLA-B27-associated uveitis/spondyloarthritis \\ Chronic inflammatory bowel diseases \\ Sarcoidosis \\ Behçet's disease \\ Vogt-Koyanagi-Harada disease}

Multiple sclerosis and anti-myelin oligodentrocyte glycoprotein (anti-MOG)-associated disease [33] Juvenile idiopathic arthritis

Tubulointerstitial nephritis and uveitis (TINU syndrome)

Celiac disease [34]

Inflammatory diseases

Systemic lupus erythematosus, systemic vasculitides (Kawasaki disease, polyarteritis nodosa, granulomatosis with polyangiitis, giant cell arteritis)

Monogenic autoinflammatory diseases: Blau syndrome, cryopyrine-associated periodic syndromes, A20 haploinsufficiency [35]

Common variable immunodeficiency [36] IgG4-related disease [37]

Kikuchi-Fujimoto disease [38]

Sweet's syndrome [39]

Autoimmune lymphoproliferative syndrome [40]

Pseudo-uveitis

Ophthalmologic entities
Trauma, intraocular foreign body

Cancer (oculocerebral lymphoma, melanoma, retinoblastoma, leukemia, metastasis)

\section{Birdshot chorioretinopathy}

Multifocal choroiditis

Pars planitis

Fuchs heterochromic cyclitis

Phacoantigenic uveitis

Posner-Schlossman syndrome

Other white dot syndromes (placoid epitheliopathy, serpiginoid choroiditis) 
Table 1. Cont.

\begin{tabular}{cc}
\hline Etiology & Specific Causes \\
\hline & Rifabutin \\
Biphosphonates \\
Drug-induced uveitis & Anti-tumor necrosis factor- $\alpha$ \\
IFN- $\alpha$ or $-\beta$ \\
BCG therapy \\
Cancer immunotherapy: BRAF and MEK inhibitors, CTLA4 and PD-1/PD-L1 checkpoint \\
inhibitors [41] \\
Vaccines [42]
\end{tabular}

Abbreviations: BCG: Bacille de Calmette et Guérin; CMV: cytomegalovirus; CTLA4: cytotoxic T lymphocyte antigen 4; HLA: human leukocyte antigen; HTLV-1: Human T-cell Lymphotropic Virus type 1; IFN: interferon; IgG4: immunoglobulin G subtype 4; PD-1: programmed cell death-1; PDL-1: programmed cell death-ligand 1.

Table 2. Diagnostic performances of the main biomarkers available in ocular sarcoidosis.

\begin{tabular}{|c|c|c|c|c|c|}
\hline Biomarker & \multicolumn{3}{|c|}{ Test Performance/Usefulness } & Limitations/Comments & References \\
\hline \multirow{3}{*}{$\begin{array}{l}\text { Lymphopenia } \\
\text { (lymphocyte count } \\
\left.<1000 / \mathrm{mm}^{3}\right)^{*}\end{array}$} & $\mathrm{Se} / \mathrm{Sp}$ & $\mathrm{PPV} / \mathrm{NPV}$ & YI/AUC & \multirow{3}{*}{$\begin{array}{l}\text { Poor Youden's index. Test } \\
\text { performances based on } \\
\text { lymphocyte count cutoff. } \\
\text { Better performance } \\
\text { coupled with serum ACE. }\end{array}$} & \multirow[b]{3}{*}{ [43] } \\
\hline & $0.15 / 0.97$ & $0.48 / 0.85$ & $0.12 / 0.71$ & & \\
\hline & \multicolumn{3}{|c|}{$\begin{array}{c}\text { Increased sensitivity }(0.19) \text {, specificity }(0.99) \text { and NPV }(0.90) \\
\text { when associated with elevated ACE. Increased sensitivity }(0.75) \\
\text { but lower specificity }(0.77) \text { with } 1470 / \mathrm{mm}^{3} \text { cutoff. Easily } \\
\text { accessible, simple, and non-invasive. }\end{array}$} & & \\
\hline \multirow{3}{*}{$\begin{array}{l}\text { Elevated ACE * } \\
(>52-61 \mathrm{UI} / 1)\end{array}$} & $\mathrm{Se} / \mathrm{Sp}$ & $\mathrm{PPV} / \mathrm{NPV}$ & YI/AUC & \multirow{3}{*}{$\begin{array}{l}\text { Optimal cutoff varying } \\
\text { from } 52 \text { UI/1 to } 61 \text { UI/l. } \\
\text { Uninterpretable if patient } \\
\text { uses ACE inhibitors. }\end{array}$} & \multirow{3}{*}[43,44]{} \\
\hline & $0.45-0.78 / 0.9$ & $0.44 / 0.89-0.97$ & $0.35-0.68$ & & \\
\hline & \multicolumn{3}{|c|}{$\begin{array}{c}\text { Highly specific and high NPV in patients referred for uveitis } \\
\text { with no known cause. Increased sensitivity/specificity coupled } \\
\text { with lymphopenia. }\end{array}$} & & \\
\hline \multirow{3}{*}{$\begin{array}{l}\text { sIL-2R (threshold } \\
\text { according to } \\
\text { manufacturer) }\end{array}$} & $\mathrm{Se} / \mathrm{Sp}$ & $\mathrm{PPV} / \mathrm{NPV}$ & YI & \multirow{3}{*}{$\begin{array}{l}\text { Not used widely enough } \\
\text { (not validated in revised } \\
\text { IWOS criteria). No } \\
\text { validated threshold. }\end{array}$} & \multirow{3}{*}{ [45] } \\
\hline & $0.98 / 0.94$ & $0.77 / 0.99$ & 0.92 & & \\
\hline & \multicolumn{3}{|c|}{$\begin{array}{c}\text { Very sensitive, high NPV, good YI. sIL2R levels replaced } \\
\text { negative tuberculin skin test in Japanese diagnostic criteria for } \\
\text { sarcoidosis. }\end{array}$} & & \\
\hline Lysozyme * & \multicolumn{3}{|c|}{$\begin{array}{c}\text { Sensibility: } 0.60-78 \text {; sensitivity: } 76-95 . \text { In systemic sarcoidosis, } \\
\text { lysozyme levels are positively correlated with sIL-2R levels and } \\
\text { ACE levels. }\end{array}$} & $\begin{array}{l}\text { High lysozyme levels can } \\
\text { be found in infectious } \\
\text { uveitis (tuberculosis, } \\
\text { syphilis). }\end{array}$ & {$[46,47]$} \\
\hline $\begin{array}{l}\text { Chitotriosidase } \\
\text { activity }\end{array}$ & \multicolumn{3}{|c|}{$\begin{array}{l}\text { No data in sarcoidosis uveitis. In patients with systemic } \\
\text { sarcoidosis, } 48.8 \mathrm{nmol} / \mathrm{h} / \mathrm{mL} \text { cutoff is associated with } 0.89 \\
\text { sensitivity and } 0.93 \text { specificity. }\end{array}$} & $\begin{array}{l}\text { High chitotriosidase } \\
\text { activity reported in other } \\
\text { pulmonary diseases } \\
\text { (COPD, asbestosis). Not } \\
\text { easily available. }\end{array}$ & [48] \\
\hline
\end{tabular}

Abbreviations: ACE: angiotensin converting enzyme; AUC: area under curve; COPD: chronic obstructive pulmonary disease; PPV/NPV: positive and negative predictive value; Se: sensitivity; Sp: specificity; YI: Youden index. * Biomarker included in the IWOS criteria.

Spa encompasses different chronic inflammatory diseases, such as ankylosing spondylitis (AS), reactive arthritis, psoriatic arthritis (PsA), arthritis associated with inflammatory bowel disease (IBD), and undifferentiated spondyloarthritis, which share common clinical features and a strong genetic association with the HLA-B27 antigen. The main symptoms are inflammatory chronic low back pain, peripheral arthritis (typically asymmetric monoarthritis or oligoarthritis predominantly affecting the joints of the lower extremities), dactylitis, and enthesitis [49]. The disease can be complicated by extra-articular manifestations, such as psoriasis, IBD, and acute AU.

Spa-associated AU is commonly reported as a recurrent unilateral nongranulomatous acute AU and affects approximately one fourth of Spa patients. It is the most common 
extra-articular manifestation of AS [50]. The risk of uveitis increases with disease duration and appears to be related to a higher cumulative exposure to inflammation [51]. Uveitis is more common in AS (23-33\%) than in PsA (7-19\%; more frequent in axial PsA than in peripheral disease) or reactive arthritis (26\%), IBD (2-5.6\%; more often in Crohn's disease) or non-radiographic axial Spa (15.9\%) [52-55]. A recent large nationwide cohort study in Sweden involving 8517 AS patients, 10,245 undifferentiated Spa (uSpa) and 22,667 PsA showed an incident rate ratios for incident acute AU significantly increased in AS (20.2), uSpa (13.6) and PsA (2.5) compared with controls [56]. Acute AU associated with Spa affects males more frequently than females and typically occurs in young adults (i.e., between 20 and 40) $[57,58]$. Other ocular manifestations, such as episcleritis and scleritis, may also occur, especially in IBD [57].

$\mathrm{BD}$ is an inflammatory disorder characterized by repeated flares of oral and genital ulcers, pustulosis, erythema nodosum, arthritis, and ocular involvement, along with potentially life-threatening vascular, gastrointestinal, and neurological manifestations [59]. BD was first described by Hulusi Behçet, a Turkish dermatologist. This ubiquitous disorder is endemic in Turkey, where the prevalence is the highest (approximately, 80370 cases $/ 100,000$ ), followed by Iraq, Iran, Korea, and Japan. This population is actually derived from the one present on the ancient Silk Road, from the Mediterranean to the Middle Eastern and Far Eastern countries [60]. Lower prevalence has been reported in North America and northern countries. In the UK, there is an estimated prevalence of 0.64 cases $/ 100,000$ [61]. The onset of symptoms typically occurs in early adulthood, but $\mathrm{BD}$ is also seen in children and older patients. In the high prevalence areas of Turkey and Middle East, incidence is higher in males. In other countries, sex distribution is variable. The disease is usually severe in young adult men. Several classification criteria exist, but the International Study Group Criteria and International Criteria for Behçet's Disease are the most widely used [62,63]. Laboratory findings may demonstrate inflammation, including elevation of acute phase reactants. A broad differential diagnosis workup is essential. Ophthalmic involvement, the most debilitating complication of $\mathrm{BD}$, occurs in about $50 \%$ of patients, usually as a relapsing-remitting disease [64]. BD uveitis is classically described as an acute, recurrent and nongranulomatous panuveitis associated with occlusive necrotizing retinal vasculitis involving both veins and arteries [65]. Less frequent ocular manifestations include conjunctivitis, conjunctival aphtosis, scleritis, and optic neuritis [66].

Sarcoidosis was first described by Besnier et al. in 1889. It is a multi-systemic disease of unknown etiology characterized by the infiltration of various tissues by non-caseating granulomas. Even if the etiology remains unknown, the mechanisms underlying granuloma formation are quite well understood [67]. Sarcoidosis can affect people from all ages and ethnicity but is more frequent in young adults with a later onset in women than in men. About $70 \%$ of cases involve patients aged between 25 and 40 years at presentation and a second peak of incidence is observed in women over 50 years old [68]. Its annual incidence is estimated between 2.3 and 11/100,000 [69]. The estimated prevalence varies from 2.17 to 160 cases per 100,000 individuals. This large variability could be explained by the different diagnostic tools used to define sarcoidosis in older series and the varying ethnicity of each cohort. Sarcoidosis course can be divided into two distinct groups: a time-limited course in two-thirds of patients, who evolve through a self-remitting disease within 12 to 36 months [68-70], and a chronic course in 10 to $30 \%$ of patients who require prolonged treatment.

Ocular involvement occurs in $25 \%$ to $50 \%$ of patients with systemic sarcoidosis [71]. Almost every structure of the eye can be affected, and clinical presentation include dry eye, conjunctival granulomas, scleritis, optic neuritis, exophthalmos, and uveitis, which is the most frequent presentation [72,73]. The characteristic signs of sarcoid uveitis are mutton-fat keratic precipitates, Koeppe's and Busacca's nodules, trabeculitis, vitreous opacities (i.e., snowballs and snow banks), segmental periphlebitis and microaneurysms on the site of inflamed blood vessels, juxtapapillary and optic disc granulomas, and choroidal nodules of larger proportions [71]. 
These three systemic inflammatory diseases have in common a possible ocular involvement. In many cases, uveitis is the first sign of the disease and the rheumatologist or the internist may play a key role in diagnosing a systemic inflammatory disease.

We hereby describe selected cases who came to our attention after referral to our ophthalmology department. In all cases the physical examination, the biological and the radiological workup allowed to establish the diagnosis of a systemic inflammatory disease. We have chosen to focus on these three systemic inflammatory diseases and to summarize their main clinical features regarding the ophthalmological presentation, the associated diagnostic approach, and their treatment.

\section{Experimental Section}

\subsection{Methods}

This article is a series of original cases and adheres to the principles of the Declaration of Helsinki of 1964 and its latest amendments. The informed consent of all participants was obtained, and the study was approved by the Local Institutional Review Board. The case reports were chosen among consecutive patients presented to our ophthalmology clinic. Each case report was selected as they were considered by the authors to be either representative of a classical clinical presentation of the disease or representative of the diagnostic issues faced by the clinician. This study received approval from the local ethics committee in February 2019 (No 19-31) and was registered on clinicaltrials.gov (NCT 03863782). In order to describe the updated management of uveitis associated with these diseases, we conducted a review of the English and French medical literature on the Medline database, using the keyword "uveitis". We selected articles published since 2016, and excluded articles written in languages other than English or French.

\subsection{Spondyloarthritis}

\subsubsection{Case Report}

The case of spondyloarthritis presented is that of a 47-year-old man with a history of diabetes mellitus, dyslipidemia, and smoking. In the last three years, he had had several episodes of unilateral AU in both eyes complicated by posterior synechia. He was referred by his ophthalmologist for this uveitis recurring monthly for the past 6 months. Visual acuity was preserved at 0 LogMAR in both eyes, and intraocular pressure was normal. Slitlamp examination revealed non-granulomatous keratic precipitates with moderate cellular anterior chamber reaction in the left eye, and moderate hypopyon (Figure 1). Fundus examination was normal and optical coherence tomography (OCT) did not reveal macular or papillary edema. The patient also reported inflammatory low back pain, which was relieved by physical exercise. Physical examination of the patient revealed back stiffness.

Laboratory testing found normal complete blood count (CBC), C-reactive protein (CRP) at $6.5 \mathrm{mg} / \mathrm{L}$, and negative Syphilis serology. Chest X-ray was normal. HLA testing revealed the presence of the HLA-B27 haplotype. Magnetic Resonance Imaging (MRI) of sacroiliac joints found signs of ankylosis in the right side, and major fatty restructuring on both sides, as well as discrete condensation in the anterior part of the articulation, reflecting a history of inflammatory rheumatism. There was no edema in favor of active sacroiliitis (Figure 2). The diagnosis of Spa was established, with a basal activity BASDAI score of 3.5. Treatment for the acute AU included topical steroids with slow tapering, and systemic treatment with sulfasalazine (SSZ) was initiated to decrease the frequency and duration of relapses. AU regressed over the first month and there was only one episode of relapse during the next three years. 


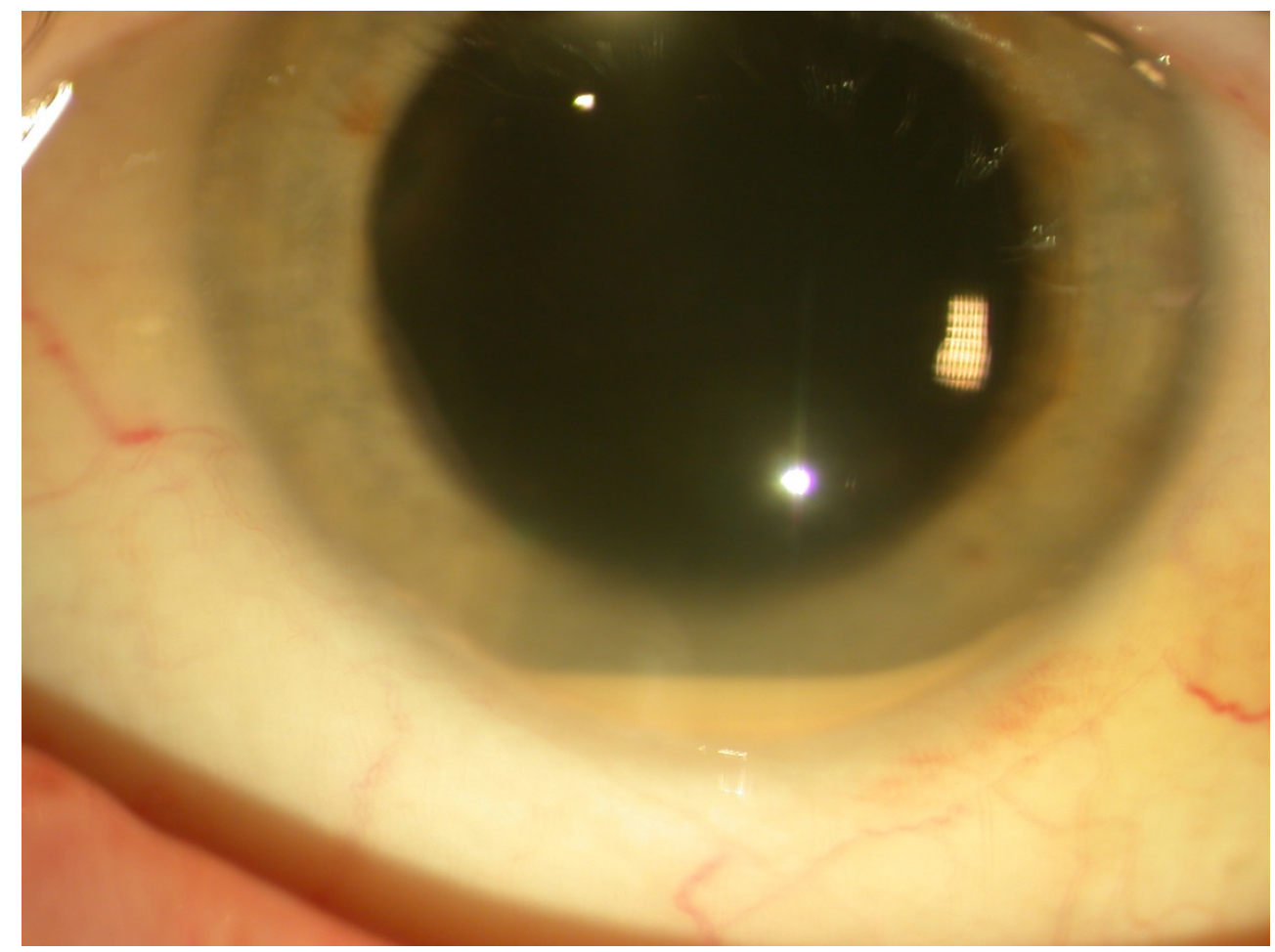

Figure 1. Slit lamp examination of case 1 showing nongranulomatous corneal precipitates with a cellular anterior chamber reaction and hypopyon.

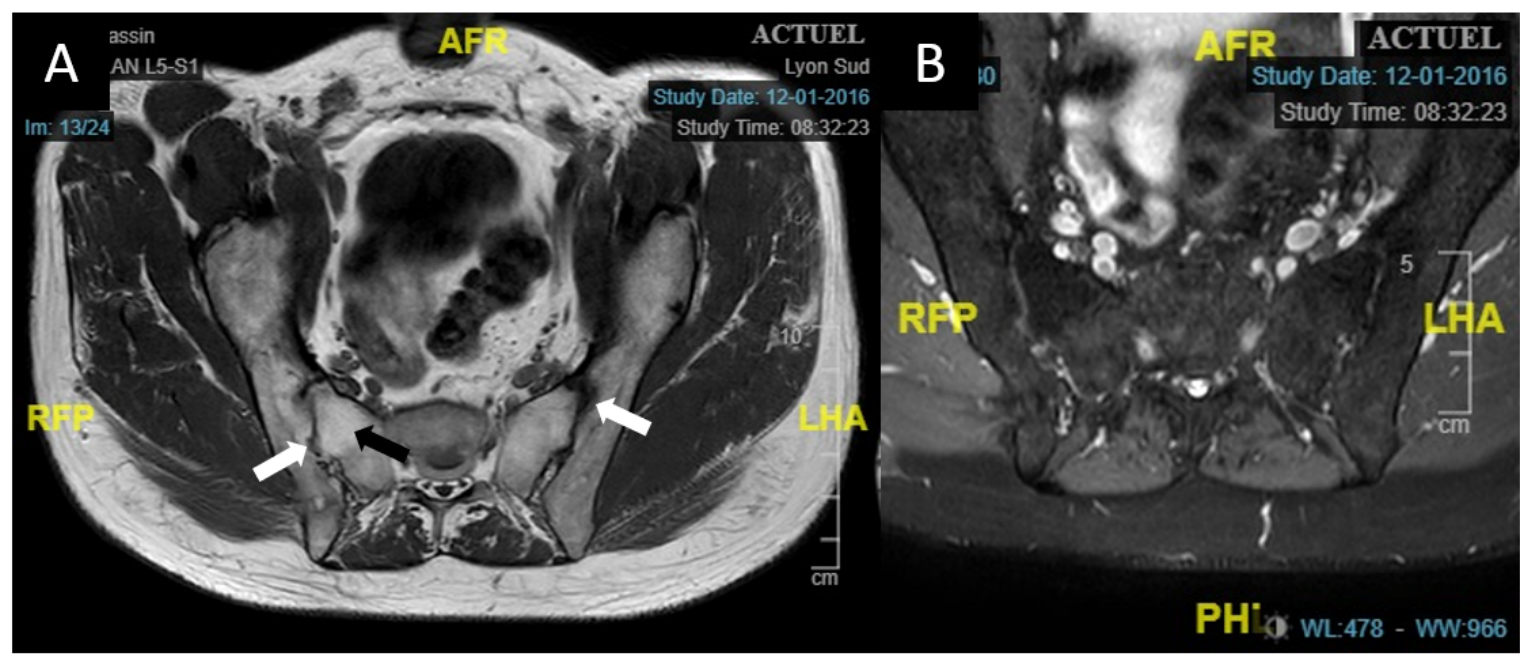

Figure 2. Axial sacroiliac MRI of case 1. (A): T1-weighted sacroiliac axial MRI of case 1 showing major joint reshaping in the form of hypo dense areas bordering the joint (white arrows) as well as ankylosis of the right sacroiliac joint with a T1 hypersignal of the subchondral bone. (B): T2 SPAIR axial sequence without hypersignal of the sacroiliac joints, indicating the absence of active involvement. Abbreviations: $A=$ anterior, $P=$ posterior, $R=$ right, $L=l e f t, H=$ head, $F=$ foot; $M R I$ : magnetic resonance imaging; T2 SPAIR: T2 Spectral Attenuated Inversion Recovery.

\subsubsection{Ophthalmic Features and Diagnosis}

The association between uveitis and HLA-B27 was first described in 1973, concomitantly with ankylosing spondylitis [74]. In the European Caucasian population, the prevalence of HLA-B27 is $7 \%$ and reaches $80 \%$ in patients with Spa [75]. The prevalence is lower in Mexicans (4\%) and African Americans (2-4\%) [76]. Uveitis associated with Spa follows a « rule of $90 »: 87 \%$ of cases are unilateral, $91 \%$ of cases are anterior, sometimes with reactive 
anterior vitritis, and $89 \%$ are acute [77]. Granulomatous lesions are never found in the anterior segment. In severe forms of acute AU, hypopyon (superimposition of white blood cells in the anterior chamber) can be seen (14-18\%) [78]. Uveitis associated with chronic inflammatory bowel disease or psoriatic arthritis, on the other hand, may be associated with anterior granulomatous lesions and tends to be more insidious in the initial phase. It is more often bilateral, chronic and usually involves the posterior segment [53]. The most frequent complications are posterior synechiae (13-90\%) [79] and cataract (7-28\%) [80]. Ocular hypertension (8-20\%), papillitis (2-18\%) and cystoid macular edema (6-13\%) are less frequent [77]. Recurrences are common (51-67\%), with a frequency ranging from 0.6 to 3.3 flares/year. The frequency of relapses tends to decrease over time, and uveitis is more often homolateral [80]. The recurrent nature of these AU is not fully explained yet; possible triggers include infections with Gram-negative bacteria, stress, seasonality, and trauma [81]. Male sex, hypopyon, accelerated ESR [78], or an associated Spa [82] are potential risk factors for frequent relapses of HLA-B27-associated uveitis. The visual prognosis of HLA-B27-associated uveitis is rather favorable since less than $2 \%$ of patients become legally blind and less than $5 \%$ become visually impaired [81]. The risk factors for visual loss are male gender, the presence of posterior synechiae at onset, the use of corticosteroid-sparing therapy or periocular corticosteroid injections, poor control of ocular inflammation, and a chronic course of the disease [83].

HLA-B27 haplotype is present in half of patients with acute AU, which is itself associated with Spa in half of the cases [75]. Testing for the HLA-B27 allele is not useful for establishing the etiological diagnosis of intermediate or posterior uveitis [84]. Only $1 \%$ of HLA-B27-positive patients have uveitis, suggesting a pathogenic role of other genetic polymorphisms (e.g., tumor necrosis factor (TNF), interleukin-10 (IL-10), or the CYP27B1 gene involved in vitamin D metabolism [85-87]). Other susceptibility loci (e.g., ERAP1, NOS2, IL23R, and MERTK) have recently been identified in a recent large genome-wide association study [88]. In a series of 175 patients with HLA-B27-associated uveitis, 136 patients were followed for Spa, and for 88 of them $(64 \%)$ the joint disease had not yet been diagnosed at the time of uveitis onset [80]. Several studies showed a delay of up to 7.9 years between the diagnosis of uveitis and the subsequent diagnosis of AS [89]. We conducted a retrospective study of 102 patients referred for etiologic evaluation after an episode of acute AU [90] and found that 21 patients (20.5\%) had Spa and $23(22.5 \%)$ were diagnosed with HLA-B27-associated uveitis. We evaluated the relevance of the criterion "inflammatory back pain" (as defined by the Berlin criteria) in the diagnosis of spondyloarthritis (according to the ASAS criteria). Low back pain was $90.5 \%$ sensitive and $75.3 \%$ specific in establishing the diagnosis of spondyloarthritis. A diagnostic algorithm (Dublin Uveitis Evaluation Tool: DUET) was developed in 101 patients and validated in 72 other patients. This tool was designed to identify criteria indicating the need for referral to a rheumatologist for patients with acute AU [91]. These criteria were: the onset of low back pain before the age of 45 years and lasting more than 3 months, or joint pain requiring referral to a general practitioner associated with a positive HLA-B27 test or known or clinically observed psoriasis. The DUET algorithm was $96 \%$ sensitive and $97 \%$ specific for the diagnosis of spondyloarthropathy and the positive and negative odds ratios were 41.5 and 0.03 , respectively. Oliveira et al. showed that $3 / 9$ patients with recurrent acute AU and no back pain had sacroiliitis on MRI [92]. Further studies are needed to determine whether a positive MRI of the sacroiliac joints, in the absence of axial symptoms, is a good predictor of Spa development. Overall, these data underline the importance for physicians to consider Spa as a cause of non-granulomatous uveitis, especially in young patients with back pain.

\subsubsection{Treatment}

The treatment of acute AU associated with Spa is not specific and involves frequent and repeated instillations of topical dexamethasone. In a minority of cases, periocular injections of glucocorticoids are necessary to control the inflammatory process. The few patients who 
do not respond to this treatment usually progress to chronic uveitis, following which they require treatment with methylprednisolone and, occasionally, methotrexate (MTX) or TNF- $\alpha$ antagonists [75]. The selection of patients eligible for maintenance therapy is based on the frequency of recurrences, the presence of residual abnormalities (which are rare), and the patient preference. The type of maintenance therapy depends on the underlying rheumatic features. In patients with frequent recurrences (at least 2-3/year) and mild rheumatic manifestations, SSZ, which had been evaluated in a small study [93] and in a randomized trial including 22 patients [94], is an option [91]. An open clinical trial on 9 patients also suggested the efficacy of MTX at an initial dose of 7.5 to $20 \mathrm{mg} /$ week to reduce the rate of recurrence of AU in patients who had more than 3 recurrences of AU in the past year [95]. A recent study of the effects of SSZ and MTX on the progression of HLA-B27 relapsing acute AU reported a significant decrease in the rates of relapses in both groups [96].

TNF- $\alpha$ antagonists prescribed to treat Spa can also prevent uveitis [97]. An overall analysis of data from four placebo-controlled trials ( 2 of etanercept and 2 of infliximab) in 655 patients who were given TNF- $\alpha$ antagonists for AS showed that the frequency of AU recurrences was 15.6/100 patient-years in the placebo group and 6.8/100 patientyears in the TNF- $\alpha$ antagonist group $(p=0.01)$ [98]. Recurrences were less frequent with infliximab than with etanercept (3.4 vs. 7.9/100 patients-years, non-significant difference). Several observational studies of patients with Spa and a previous history of acute AU have shown a significant decrease of approximately $50 \%$ in the rate of uveitis recurrence with TNF- $\alpha$ antagonists, including infliximab, adalimumab (ADA), certolizumab pegol and golimumab but a lesser effect of the soluble TNF receptor fusion protein etanercept [99-101]. In addition, several studies suggested that etanercept may cause inflammatory eye disease, including acute AU and scleritis, in patients without a history of inflammatory joint disease predisposing to uveitis $[102,103]$. The analysis of a German pharmacovigilance database showed a significant increase in the risk of uveitis with etanercept compared to ADA or infliximab [104]. According to the World Health Organization (WHO) causality assessment system, etanercept may be causally related to uveitis independently from age, gender, and HLA haplotype. This adverse event is rare $(<1 \%)$ and carries no risk of vision loss. Overall, these data have shown that etanercept is less effective in preventing AU compared to the anti-TNF monoclonal antibodies [105]. However, this difference in efficacy was not considered sufficient by the American and European Rheumatology organizations to recommend a treatment with the latter drugs rather than etanercept in patients with an isolated episode of uveitis. [106]. TNF monoclonal antibodies are recommended over etanercept for patients with frequently recurrent AU [106] or, in our opinion, should be preferred in patients with a previous history of severe uveitis related to HLA-B27. Finally, rheumatologists should be aware that TNF- $\alpha$ antagonists might induce a sarcoid-like reaction that may be associated with the development of uveitis. [107]. Vedolizumab, a humanized murine antibody against integrin $\alpha 4 \beta 7$ (a protein involved in the migration of leukocytes to the gastrointestinal tract) is approved for the treatment of IBD. In a database analysis, this treatment was associated with a higher frequency of uveitis than in patients treated with TNF- $\alpha$ antagonists. [108].

We recently reported an open-label strategy to prevent the recurrences of HLA-B27associated AU in 61 of 101 patients (60.4\%) with Spa-associated uveitis [109]. The use of SSZ as a first-line treatment for the ophthalmologic indication reduced uveitis recurrences in $82 \%(23 / 26)$ of patients. MTX and TNF- $\alpha$ antagonists were initiated for a rheumatologic indication in $81.8 \%(9 / 11)$ and $100 \%$ of patients $(13 / 13)$, respectively. The annual rate of uveitis relapse decreased significantly in patients on SSZ ( 0.37 relapses/year versus 2.46 relapses/year at baseline; $p<0.001)$ and MTX (1.54 relapses/year versus 4.17 /year; $p=0.008)$. The use of anti-TNF- $\alpha$ agents for ophthalmologic purposes was exceptionally necessary (2 patients).

In addition to TNF- $\alpha$, several studies have shown the importance of IL-17 and IL$12 / 23$ in the pathogenesis of axial Spa [110]. Based on an analysis of pooled data from three previous studies (Measure 1, 2 and 3), Deodar et al. did not show an increased 
risk of AU in patients taking secukinumab, a humanized monoclonal antibody against IL-17A, for Spa [111]. Other IL-17A inhibitors, such as ixekizumab, have shown promising results [112]. Ustekinumab, a monoclonal antibody, directed to the p40 subunit of IL-12 and IL-23, is approved by the European Medicines Agency (EMA) and the Food and Drugs Administration (FDA) for PsA and is currently under study for uveitis (www.clinicaltrials. gov NCT02911116 and French USTEKINISU trial).

\subsection{Behçet's Disease \\ 2.3.1. Case Report}

The case of BD that we present is a 39-year-old male, with a history of smoking and episodes of bilateral acute AU in the last 5 years, treated with topical steroids. No etiology had been demonstrated in previous evaluations. He presented to our emergency consultation with a red and painful left eye for the past 2 days, associated with vision loss. Best corrected visual acuity was $0 \operatorname{LogMAR}$ in the right eye, and 1.0 LogMAR in the left eye. Intraocular pressure was normal and slit lamp examination revealed bilateral acute AU with non-granulomatous keratic precipitates, mild cellular anterior chamber reaction, and no posterior synechiae. Fundus exam revealed mild vitritis, stage 3 bilateral papilledema, venous beading in the posterior pole and periphery, and several patches of perivascular retinal whitening consistent with ischemia. There was a larger yellow-white patch of retinal opacification in the left posterior pole associated with intraretinal hemorrhage consistent with retinal necrosis (Figure 3).

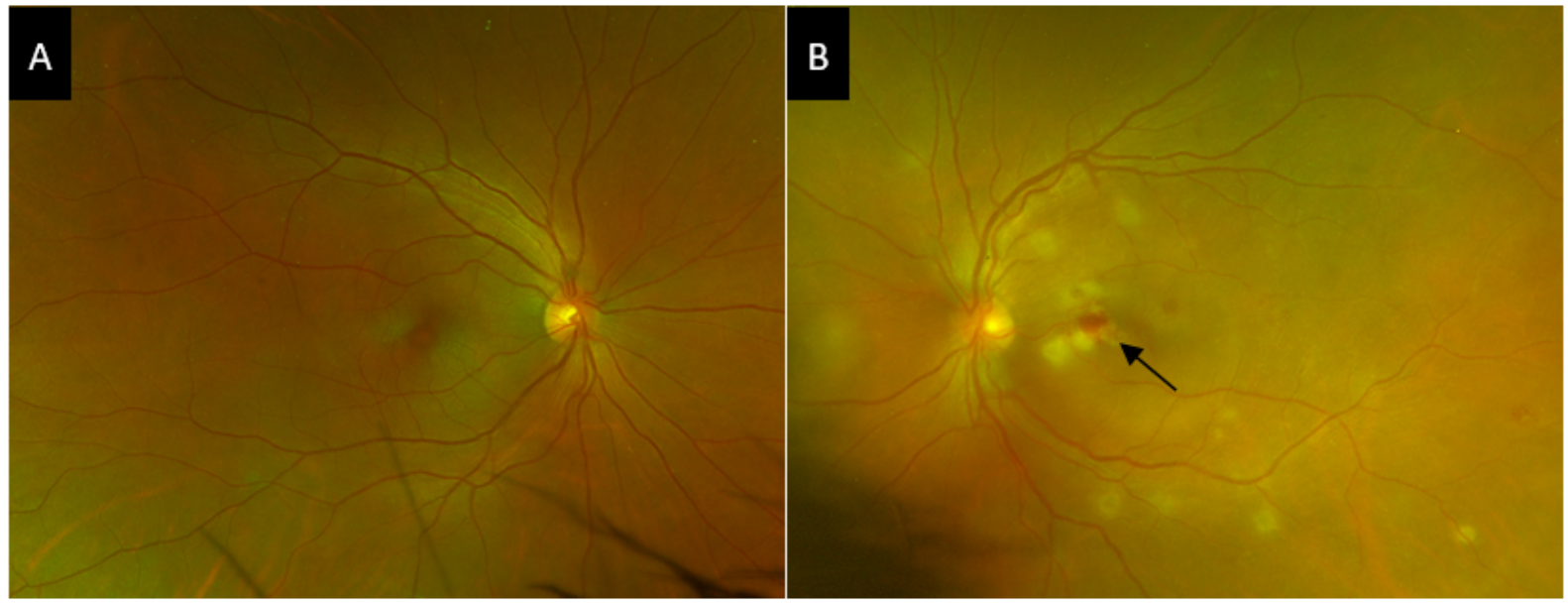

Figure 3. Wide field fundus photograph of the right eye of the case 2 patient. (A), Widefield fundus photograph of the right eye showing no signs of intermediate or posterior uveitis. (B), Widefield fundus photograph of the left eye showing multiple patchy subretinal white spots and a nodule of retinal necrosis with hemorrhage (black arrow).

OCT of the right macula found mild intraretinal edema (Figure 4A) and in the left macula there was a large serous retinal detachment, a nodule of intraretinal hyper-reflectivity with loss of differentiation of the inner retinal layers at the site of retinal necrosis, as well as intraretinal edema, and hyperreflective dots in the vitreous (Figure 4B).

Fluorescein angiography revealed early loss of perfusion at the level of the necrotic nodule in the left eye, and bilateral diffuse capillaritis associated with papillitis (Figure 5A,B). Indocyanine green (ICG) angiography was normal in the right eye and showed several hypofluorescent spots on the middle and late sequences in the posterior pole of the left eye, consistent with patches of choroiditis (Figure 5C,D). 


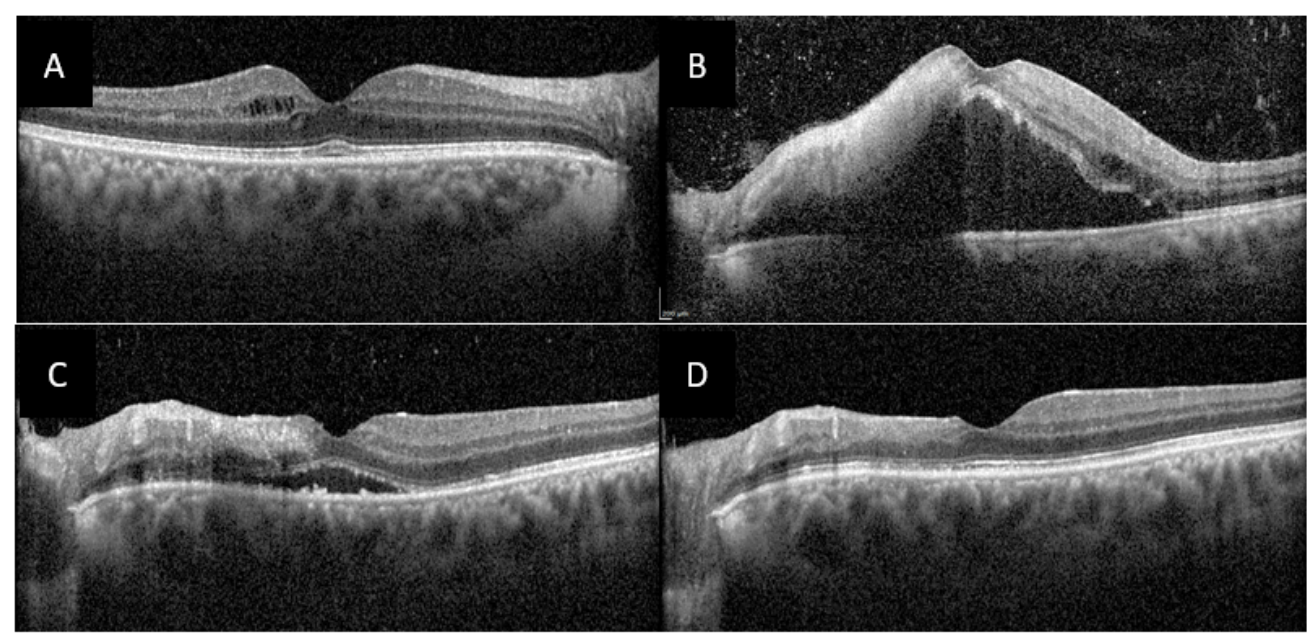

Figure 4. Optical coherence tomography (OCT) of both macula of case 2 patient. (A), OCT of the right macula showing a few cysts of intraretinal edema. (B), OCT of the left macula showing a large serous retinal detachment, a hyperreflective nodule in the inner retinal layers, intraretinal edema and numerous hyperreflective dots in the vitreous. (C), OCT of the left macula at 1-month follow-up showing partial regression of subretinal fluid. (D) OCT of the left macula at 3 months follow-up showing complete regression of macular edema, and atrophy of internal retina in place of the hyperreflective nodule.

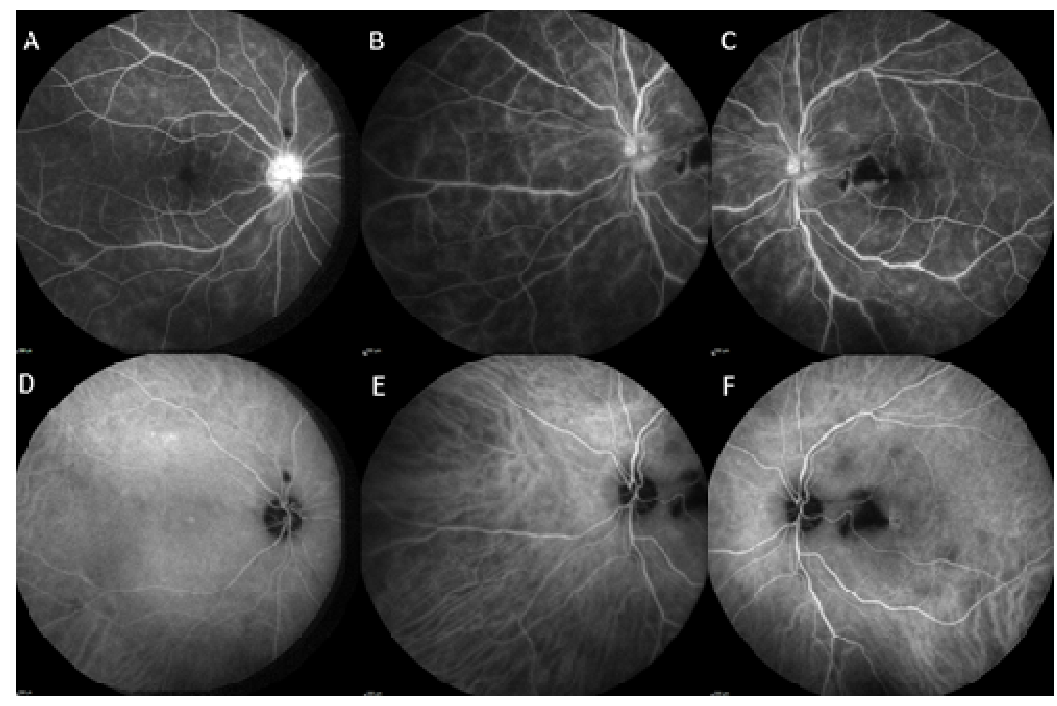

Figure 5. Fluorescein angiogram of both eyes of case 2 patient. Fluorescein angiogram of the right eye (A) in late sequence showing diffuse capillaritis and papillitis. Fluorescein angiogram of the left eye $(B, C)$ in the same sequence showing central and peripheral capillaritis, papillitis, and a mask effect due to hemorrhage in a retinal necrosis nodule. Indocyanine green (ICG) angiogram in middle sequence of the right eye (D) showing no choroidal involvement, and of the left eye (E,F) showing predominantly macular spots of hypofluorescence corresponding to choroiditis.

The patient was addressed on the same day to the internal medicine department. Medical history revealed past episodes of oral ulcers, and general exam found a few eczematous skin lesions, pseudofolliculitis, and was otherwise unremarkable. Laboratory workup showed normal CBC, liver enzymes, kidney function, CRP and angiotensin converting enzyme (ACE). Human immunodeficiency virus (HIV) and syphilis testings were negative, as well as Interferon Gamma Release Assay, Lyme disease and Bartonella. Anterior chamber tap of the left eye for herpesviruses 1 and 2 PCR and universal PCR was negative. HLA typing found no B51 nor B27 haplotype. Chest computed tomography (CT) was unremarkable, but 
brain MRI found multiple and bilateral subcortical hyperintense T2 spots. Spinal tap found only mild hyperproteinorachia $(0.48 \mathrm{~g} / \mathrm{L})$. The diagnosis of $\mathrm{BD}$ was established according to international criteria given the presence of oral aphtosis and uveitis.

Initial treatment comprised intravenous acyclovir pending the results of anterior chamber tap. Upon negative results, methylprednisolone pulses were administered over three days followed by slow tapering with oral corticosteroids and treatment with azathioprine and infliximab. Colchicine was also started in prevention of recurring oral ulcers. The ophthalmologic signs rapidly decreased with complete regression of AU, vitritis, macular edema (Figure 5C) and vasculitis at 1 month, and persistence of a mild bilateral papillitis and retinal scarring in place of the necrosis nodule in the left eye at 3 months follow-up (Figure 5D). At last visit 6 month later there had been no relapse in uveitis or oral ulcers.

\subsubsection{Ophthalmic Features and Diagnosis}

The proportion of patients with BD who experience ocular manifestations varies across studies from $28 \%$ to $50 \%$ [113], with a higher incidence in men towards the end of the third decade of life [114]. Uveitis can be either inaugural (10-20\%) or develop within 2 to 3 years after the onset of oral ulcers. BD represents $4.2 \%$ of all uveitis cases in the ULISSE study [29] and $1.8 \%$ to $6.1 \%$ of severe uveitis treated in European specialized centers [18-20]. Among patients with BD's uveitis, 90\% have posterior uveitis or panuveitis and $78 \%$ have bilateral involvement; furthermore, $89 \%$ have retinal vasculitis and $44 \%$ macular edema [114], which can cause visual impairment (with blindness in 13-21\% of cases) [64,115]. Visual prognosis is particularly poor in patients with more than three ocular attacks per year, strong vitreous opacity, and exudates within the retinal vascular arcade [116]. Isolated AU is more rarely reported, and mainly affects women (5-10\%) [114]. Although hypopyon is considered to be a hallmark of the disease, it has been observed in only 9 to $10.4 \%$ of patients in two recent reports $[117,118]$.

The diagnosis of BD has a clinical basis. According to the International Study Group Criteria, in addition to oral ulcers (mandatory criterion), the patient must meet at least two minor criteria (genital ulcers, uveitis, erythema nodosum or papulopustular lesions, and positive pathergy test) and no evidence of differential diagnosis [63]. To compensate for the low sensitivity of these criteria, estimated at $86.2 \%$ in a large series of patients (2069 BD and 1519 controls) [66], International Criteria for BD (ICBD) have been developed, revised, then published in 2014 [59]. According to those criteria, a diagnosis of BD is established when a patient scores at least 4 points in the following list of items: oral aphthosis 2 points, genital aphthosis 2 points, ocular manifestations 2 points, skin manifestations (pseudofolliculitis, erythema nodosum, skin aphthosis) 1 point, vascular manifestations 1 point, neurological manifestations 1 point, and positive pathergy test 1 point. A subsequent study in Iran confirmed that the International Criteria for BD was superior to International Study Group Criteria in terms of sensitivity and accuracy [119]. Other clinical and biological features may help orientate the diagnosis of BD. Among them, the presence of HLA B51 allele is a classical biological marker. Nevertheless, the performance of HLA typing in BD in order to evidence the HLA B51 allele suffers from a low sensitivity (51\%) with a specificity of $71 \%$ [59]. Tugal-Tutkun et al. have recently developed an algorithm for the diagnosis of BD uveitis based on ocular findings only, using retrospective and prospective analysis data from two independent uveitis populations with and without BD [120]. Ten items with a diagnostic odds ratio $>5$ were identified. The items with the highest ratios included superficial retinal infiltrate, evidence of occlusive retinal vasculitis, diffuse retinal capillary leakage, and the absence of granulomatous AU or choroiditis in patients with vitritis. These results need to be validated in a larger clinical cohort to assert their performance in different contexts.

\subsubsection{Treatment}

The treatment of Behçet's uveitis aims to obtain a complete disappearance of the ocular inflammation. Patients with isolated AU can be treated with topical corticosteroids [121]. 
According to 2018 EULAR recommendations for the management of BD, systemic immunosuppressive drugs such as azathioprine could be considered if poor prognosis factors are present including young age, early onset, and male gender. The involvement of the posterior segment justifies systemic glucocorticoid therapy in combination with azathioprine. ciclosporin-A is another option to preserve visual acuity and to prevent relapses [122]. Side effects of ciclosporin-A such as renal dysfunction and hypertension should be kept in mind. There is also evidence of a possible association between the use of ciclosporin-A and the development of neurological BD [123]. Methotrexate is also useful and is a possible alternative to azathioprine and ciclosporin-A [62].

However, these treatments are inadequate in patients with severe retinal vasculitis [124]. Acute sight-threatening uveitis and severe uveitis (e.g., severe inflammatory optic neuropathy, macular ischemia, unilateral uveitis in monophthalmic patients) are emergencies for patients with BD. Methylprednisolone pulses (250-1000 mg/d for 1-3 days) are recommended [122]. The prognosis of severe or refractory forms has been radically changed by the introduction of TNF- $\alpha$ antagonists, mainly infliximab $[97,125,126]$. These drugs are effective in $80 \%$ to $90 \%$ of cases, usually within a few days [125]. According to the 2018 EULAR recommendations, patients with an initial or recurrent episode of acute sight-threatening uveitis should be treated with infliximab or interferon- $\alpha$ [121]. A recent Spanish study comparing infliximab and ADA in refractory uveitis due to BD showed that both drugs were equally effective, although ADA appeared to be associated with a better outcome in terms of anterior chamber inflammation, vitritis, best-corrected visual acuity and drug retention rate after 1 year of follow-up [127]. Interferon- $\alpha 2 a$ is also effective in posterior uveitis due to $\mathrm{BD}$, with 2 to 4 weeks delay in onset of action [128]. In contrast to experience with TNF- $\alpha$ antagonists, interferon- $\alpha 2 a$ induces a sustained remission, which may persist after discontinuation of treatment ( $20 \%$ to $58 \%$ of cases) [129], and is associated with less frequent relapses in elderly patients [130]. Yalçindag and Köse recently compared infliximab and interferon in a retrospective study of 53 patients and found no significant difference in the control of intraocular inflammation [131].

Although another study of an IL-1 inhibitor (gevokizumab) for BD uveitis has failed to show efficacy, canakinumab and anakinra appear to be useful alternatives in small groups with BD uveitis, but further trials are needed to demonstrate their efficacy [132-134]. Pegylated interferon- $\alpha$, daclizumab, and secukinumab did not meet the primary endpoints for uveitis compared with placebo in three randomized trials [135-137]. Rituximab has shown positive preliminary results, in combination with prednisone and MTX, in a singleblinded trial of 20 patients [138], but sufficiently powered trials are needed to provide evidence of efficacy.

Intravitreal glucocorticoids injections may be an option in patients with unilateral flares as an adjunct to systemic treatment [121]. However, complications are frequent (49\%), with cataracts (36\%), increased intraocular pressure (43\%), and glaucoma (9\%) [128]. An algorithm for the management of Behçet's uveitis reflecting the approach of the French uveitis specialists is shown in Figure 6. In an open-label study, Martin-Varillas et al. showed that optimization of ADA, by progressively increasing the interval between doses, was effective, safe and cost-effective [139]. 


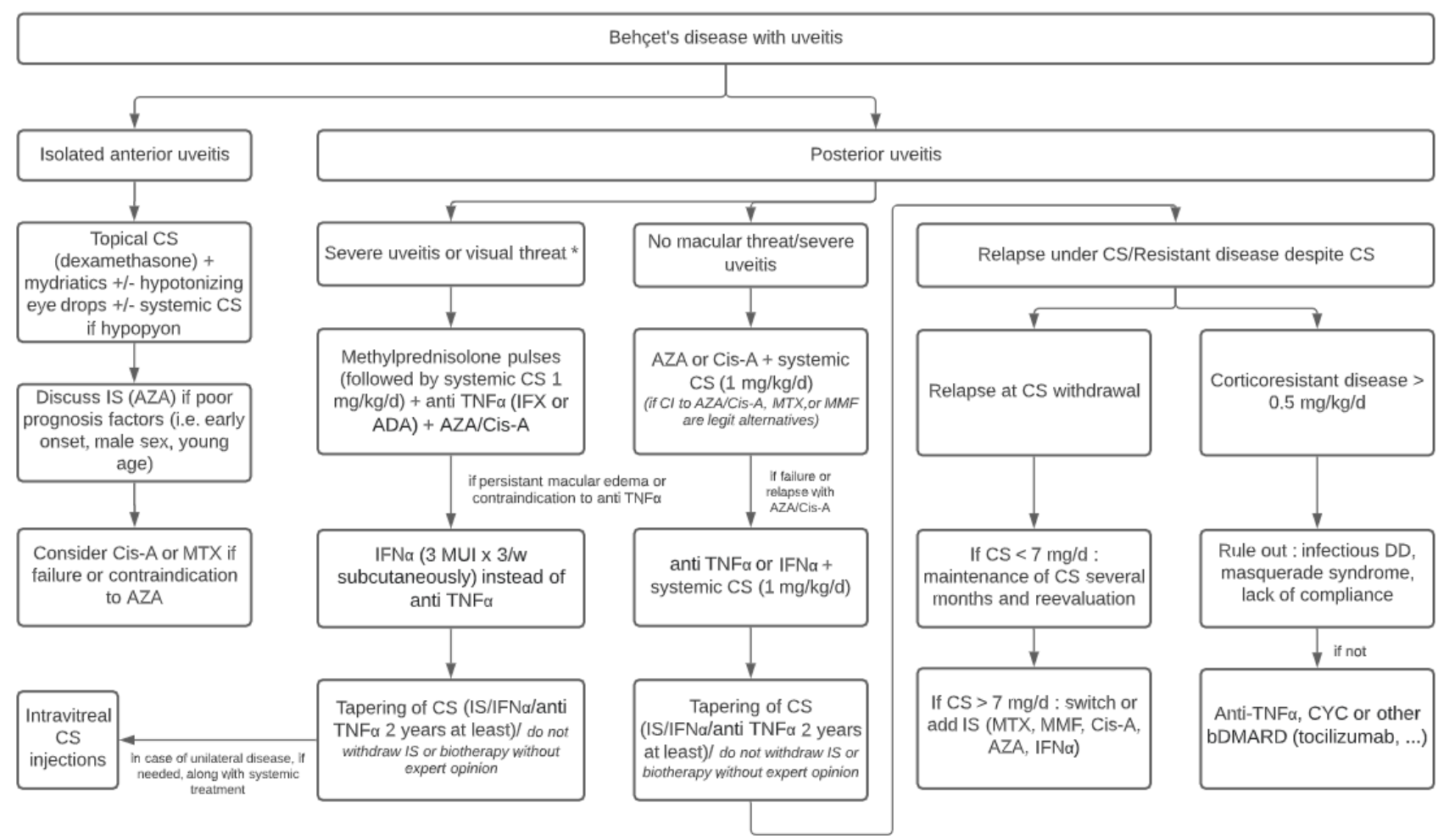

Figure 6. Algorithm for management of Behçet's uveitis. Abbreviations: ADA: adalimumab; AZA: azathioprine; bDMARD: biologic disease modifying anti rheumatic drugs; Cis-A: ciclosporine A; CS: corticosteroids; CYC: cyclophosphamide; IFN: interferon; IFX: infliximab; IS: immunosuppressants; MMF: mycophenolate mofetil; MTX: methotrexate; MUI: million international units; TNF: tumor necrosis factor. * optic neuropathy, macular edema with visual acuity $<20 / 200$ or vasculitis with retinal ischemia.

\subsection{Sarcoidosis}

\subsubsection{Case Report}

The sarcoidosis case presented is that of a 55-year-old woman, self-referred to our ophthalmology clinic in the context of a red and painful left eye associated with a visual loss. The best corrected visual acuity was 0.2 LogMAR in the right eye and 0.4 LogMAR in the left eye. Intraocular pressure was $15 \mathrm{mmHg}(9-21 \mathrm{mmHg})$ in both eyes. Slit lamp examination revealed on the left eye numerous large mutton fat keratic precipitates, predominantly at the inferior pole, with moderate cellular anterior chamber reaction and a posterior synechia (Figure 7). The right eye had sequelae of posterior synechia. No iridal nodule was seen. Fundus examination revealed bilateral mild vitritis with inferior snowballs, cystoid macular edema, and multiple inferior and peripheral waxy spots (Figure 7A) typical of multifocal choroiditis. OCT confirmed the presence of a large cystoid macular edema (Figure 7B) and papilledema. Fluorescein angiography showed progressive filling of macular edema cysts and papillitis (Figure 7A,B), diffuse capillaritis (Figure 7C) and an association of hypofluorescent and hyperfluorescent spots in the inferior periphery, corresponding to choroidal granulomas at different stages of evolution (Figure 7D). ICG angiography revealed multiple choroidal granulomas that were better visualized in early phase at the posterior pole (Figure 7E,F) and at the periphery (Figure 7G,H). OCTAngiography of the posterior pole at the level of the choriocapillaris revealed areas of low flow co-located with hypofluorescent ICG spots, corresponding to choroidal granulomas. It has been shown recently that OCT-Angiography has a 94\% sensitivity for the detection of posterior pole choroidal granulomas [140]. 

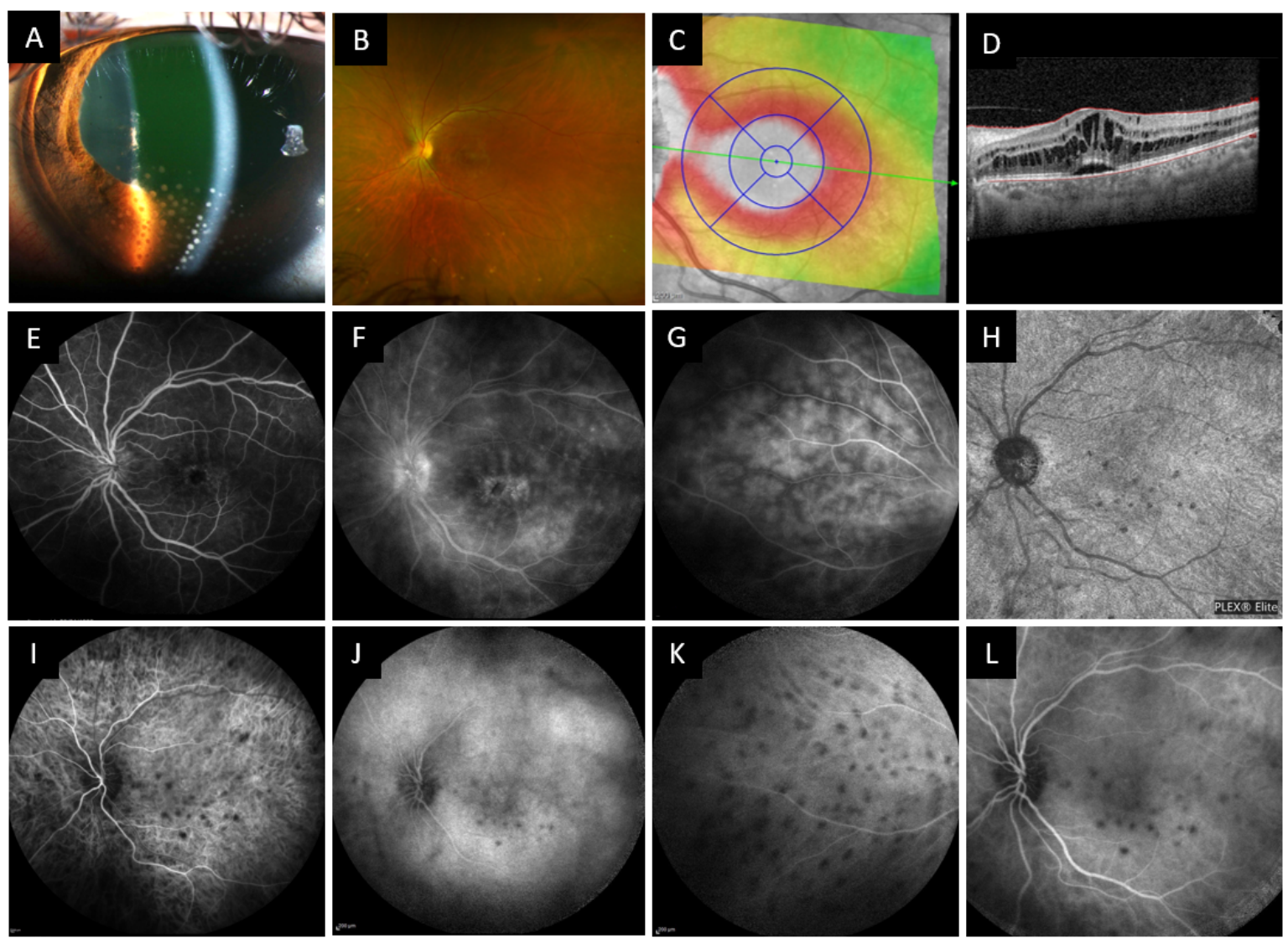

Figure 7. Slit lamp examination, wide field fundus photography, OCT, fluorescein angiography and OCT angiography of case 3 patient. (A) Slit lamp examination showing numerous mutton fat keratic precipitates with anterior chamber reaction and posterior synechiae. (B) Wide field fundus photography showing macular edema and inferior yellow-white waxy spots. (C) OCT Thickness mapping of the macula and B-scan (D) showing cystoid macular edema with retro foveolar subretinal detachment. (E-G) Fluorescein angiography showing signs of cystoid macular edema, papillitis, capillaritis and choroidal granulomas. (I-K) Indocyanine angiography showing hypofluorescent spots most visible in the early phase, present at the posterior pole and periphery. (H) OCT angiography of the choriocapillaris at diagnosis showing spots of reduced choriocapillary flow corresponding to choroidal granulomas on the ICG angiogram (L).

The patient was referred to the internal medicine department. The non-ophthalmological clinical examination was unremarkable. Laboratory testing found normal ESR and CRP, as well as normal serum protein electrophoresis. CBC was normal; Interferon Gamma Release Assay, HIV, Syphilis, Borrelia, and Lyme disease tests were negative. ACE was elevated at 98 $\mathrm{U} / \mathrm{L}(12-68 \mathrm{U} / \mathrm{L})$ and Lysozyme was elevated at $21.3 \mathrm{mg} / \mathrm{L}(<15 \mathrm{mg} / \mathrm{L})$. Chest CT evidenced bilateral hilar lymphadenopathy, without interstitial infiltrates or pulmonary nodules. Salivary gland biopsy found lymphocytic sialadenitis without granuloma. Transbronchial needle biopsy of lymphadenopathy evidenced multiple noncaseating granulomas compatible with sarcoidosis on two of the four biopsies. Given the severity of the posterior involvement and the significant vision loss, the patient underwent a course of intravenous methylprednisolone pulses over 3 days, followed by slow oral tapering of prednisolone, and topical steroids for the management of AU.

During follow-up, the patient experienced bilateral regression of her AU as well as regression of angiographic and OCT signs. The visual acuity at last visit was 0.2 LogMAR in the right eye and 0.2 LogMAR in the left eye.

\subsubsection{Ophthalmic Features and Diagnosis}

Sarcoid uveitis is generally bilateral (75-90\%) with the same characteristics and clinical course in both eyes [72,141]. AU is usually the most common anatomical form of 
intraocular inflammation (41-75\% of sarcoid uveitis) [72,142,143], followed by posterior, intermediate uveitis, and panuveitis. Nevertheless, recent reports from tertiary centers identified panuveitis as the most commonly encountered subtype of uveitis in sarcoidosis patients [141,144]. AU is usually chronic, bilateral, granulomatous, and associated with anterior and posterior synechiae. Granulomatous AU is classic but not specific to sarcoidosis, as it may be seen in uveitis related to other causes, such as infections (tuberculosis, syphilis, and herpes viruses) and inflammatory disorders (multiple sclerosis and VKH). In contrast, hypopyon is atypical of sarcoidosis-associated uveitis [145]. Chronic anterior sarcoid uveitis can lead to band keratopathy, glaucoma, and cataract formation. This presentation is the paradigm of sarcoid uveitis but, statistically, non-granulomatous uveitis is a more frequent presentation (being twice as frequent in some series) [146]. Indeed, patients with Löfgren's syndrome most often present with bilateral acute and non-granulomatous AU. In these cases, the inflammation is often self-limiting, as is the systemic disease.

Intermediate uveitis is seen in $6 \%$ to $19 \%$ of patients with sarcoid uveitis [141,144,146]. On the other hand, sarcoidosis is responsible for $7-18 \%$ of all intermediate uveitis cases, which makes it one of the two most important systemic associations along with multiple sclerosis $[18,147]$. Vitreous opacities may include "snow-balls" and/or "string of pearls" and these features are highly suggestive of a granulomatous process.

In sarcoid posterior uveitis, the retinal lesions usually accompany choroidal inflammation; however, retinal or choroidal involvement can be isolated. Posterior uveitis is observed in $7-28 \%$ of patients with ocular sarcoidosis [72,141]. Characteristic findings include retinal periphlebitis associated with segmental cuffing, extensive sheathing, and perivenous infiltrates, referred to as "candle-wax drippings" (70\% of posterior sarcoid uveitis cases). These lesions may be subclinical and only visible on fluorescein angiography. Capillary closure and ischemia are uncommon. Peripheral and, sometimes, central multifocal choroiditis is the second hallmark of sarcoidosis at the posterior segment. These lesions are small (less than one-half disk diameter), creamy or white, rarely affecting the macula but predominantly post-equatorial, and more commonly in the inferior fundus. Upon resolution of the granuloma, an area of pigmented epithelial atrophy may occur [71].

Optic-disc nodule(s)/granuloma(s) or a solitary choroidal nodule are rare manifestations, even in sarcoidosis, but are highly specific of the disease [148]. Posterior sarcoid uveitis is associated with neurological involvement in up to $27 \%$ of cases [149]. A thorough fundus examination should be performed in all patients suspected of having posterior sarcoid uveitis to differentiate it from optic neuritis. Finally, bilateral papilledema, caused by intracranial hypertension in the context of neuro-sarcoidosis with hydrocephalus, is a classic pitfall since it can mimic features of posterior segment involvement whereas the papilledema is more "mechanical" than inflammatory.

Panuveitis represents $9 \%$ to $48 \%$ of sarcoid uveitis cases [71,141,144]. Conversely, sarcoidosis is responsible for about $7 \%$ to $27 \%$ of panuveitis cases and is one of the most frequent etiology in Europe and Japan, along with BD and tuberculous uveitis $[18,46]$.

Physicians should be aware of tattoo-associated uveitis with granulomatous tattoo reaction, with or without systemic sarcoidosis. As shown in the medical literature, this entity becomes more frequent with the increasing popularity of tattooing and affected one patient in our study [150].

Few studies have described long-term systemic outcomes in patients with sarcoid uveitis [144,151,152]. In the most recent studies, $62 \%$ to $78.8 \%$ of patients had isolated sarcoid uveitis. Of these patients, $7.7 \%$ to $32.9 \%$ developed extraocular involvement, the most common being in the lungs and skin $[144,151]$. Han et al. recently reported on a series of 249 patients with uveitis and found that 4 of the 19 patients (21\%) with presumed sarcoidosis had ventricular tachycardia requiring cardiac defibrillator implantation [153]. These data are inconsistent with recent studies on patients with sarcoid uveitis, which report a prevalence of cardiac involvement in $1 \%$ to $2 \%$ of patients [141].

Sarcoid uveitis is associated with a favorable visual outcome, with most patients experiencing mild or no visual impairment $[71,151]$. However, $2.4 \%$ to $10 \%$ of patients 
with sarcoid uveitis develop severe visual impairment $[142,144,151]$. The main cause of visual loss is cystoid macular edema $[151,154]$. Poor visual prognosis has been associated with advanced age, African American origin, female sex, underlying chronic systemic disease, posterior ocular segment involvement, multifocal choroiditis, the presence of cystoid macular edema, persistent ocular inflammation, and glaucoma $[149,151,152,154]$.

The evaluation of patients with uveitis and suspected sarcoidosis should begin with non-invasive laboratory and radiological tests and progress to invasive tests if necessary. Increased ACE levels and lymphopenia, as lysozyme, soluble IL-2 receptor and chitotriosidase could be useful for the presumptive diagnosis of sarcoid uveitis (Table 2). The sensitivity of chest-CT for biopsy-proven pulmonary sarcoidosis is higher than that of chest X-ray (91\% to $100 \%$ versus $41 \%$ to $69 \%$, respectively) [142,155-159]. Chest-CT is particularly useful in patients over 50 years of age [160-162]. It suggests sarcoidosis if it shows bilateral hilar and/or mediastinal lymph nodes, perilymphatic micronodules, or other parenchymal lung abnormalities [162]. Several studies have demonstrated the value of combining ACE with chest X-ray or chest CT for the diagnosis of sarcoid uveitis [142,161]. A modification of these serum markers and/or the presence of mediastinal lymphadenopathy was observed in almost all patients with histologically-proven sarcoidosis [142]. In a series of 19 patients, we first demonstrated the value of 18-FDG PET to detect occult sites of the disease in patients with unexplained uveitis. As illustrated by our observation, this exam can help determine the most accessible site for biopsy. In a subsequent study of 54 patients with chronic uveitis suggestive of sarcoidosis, we showed that $31 \%$ of patients had an increased uptake of 18F-FDG in the mediastinal lymph nodes consistent with sarcoidosis [163]. The diagnostic performance of 18F-FDG PET was higher in elderly patients (especially over 56 years of age), in patients with posterior synechia and in patients with mediastinal lymphadenopathies on the chest CT. More recently, we reported that nearly $30 \%$ of our patients with suspected sarcoid uveitis and who had a normal chest CT, had hypermetabolic foci on their 18F-FDG PET consistent with sarcoidosis [164]. This led to a change in diagnostic classification in approximately $21 \%$ of patients. This work showed that older age at diagnosis, the presence of synechiae and elevated ACE were significantly associated with abnormal 18F-FDG PET findings. Among invasive tests, a minor salivary gland biopsy is only contributive for the histologic diagnosis of sarcoidosis in uveitis patients with increased serum ACE level and/or compatible imaging findings [165]. Several studies have suggested that bronchoalveolar lavage (BAL) fluid analysis may be useful in the diagnosis of sarcoidosis, even when chest imaging is normal $[166,167]$, but bronchial biopsy are never positive in this situation. The sensitivity of bronchial biopsy in patients with suspected ocular sarcoidosis ranges from $42 \%$ to $61 \%$ for radiologic stage 0 and from $43 \%$ to $84 \%$ for stage I [168-170]. Endobronchial or endo-esophageal fine needle aspiration of the mediastinal nodes guided by ultrasound may help delay mediastinoscopy $[72,161]$.

Several non-invasive biomarkers may also be useful in diagnosing ocular involvement in sarcoidosis (Table 2). ACE level has been shown to be an efficient biomarker when associated with lymphopenia [43]. These two laboratory tests are available at most centers worldwide. The optimal threshold varies (according to studies with different receiver operating characteristic (ROC) curves) between 52 and $61 \mathrm{UI} / \mathrm{l}$. ACE level benefits from a high negative predictive value (NPV) (from $89 \%$ to $97 \%$ in patients referred for uveitis), thus making the diagnosis of sarcoidosis very unlikely in patients with uveitis and normal ACE $[43,44]$. Cotte et al. demonstrated that the presence of lymphopenia can improve the PPV of the test from $45 \%$ to $74 \%$ with the disadvantage of a less sensitive test with a decreasing sensitivity from $46 \%$ to $19 \%$. Test performances were not validated with dedicated studies for ocular sarcoidosis. Sahin et al. demonstrated that elevated serum lysozyme was associated with ocular sarcoidosis but also with other infectious uveitis including tuberculosis and syphilis [47]. Given the similar sensitivity and specificity compared with ACE levels and its interest combined with chest imaging, lysozyme can be useful in diagnosing ocular sarcoidosis. Its usefulness could be theoretically greater in patients treated with ACE inhibitors for whom ACE levels are uninterpretable [46,72]. 
Those three biomarkers are included in the revised IWOS criteria for the diagnosis of ocular sarcoidosis [171]. Other biomarkers are available for the diagnosis of ocular sarcoidosis such as chitotriosidase activity and serum IL-2 receptor (sIL-2R) levels. Given its poor accessibility, it is difficult to routinely recommend chitotriosidase activity assessment even if its diagnostic performances seems interesting in systemic sarcoidosis [48]. No data is available for the diagnosis of ocular sarcoidosis. Similar accessibility issues are encountered with sIL-2R level assessment. Unlike the chitotriosidase activity assessment, sIL-2R level was evaluated in ocular sarcoidosis. Gundlach et al. reported that sIL-2R measurement had higher sensitivity, specificity and NPV compared with ACE [45]. Accordingly, its Youden index is the highest among sarcoidosis biomarkers (a Youden index near one indicating a highly performant test). However, the revised IWOS criteria are currently excluding sIL2-R measurement on the basis of its poor accessibility [171]. CD4/CD8 ratio in vitreous fluid could also be an interesting biomarker but was considered to be too invasive to be routinely recommended for the diagnosis of ocular sarcoidosis by the IWOS experts.

Based on previous studies on the relevance of laboratory and imaging findings to assess sarcoidosis in uveitis patients, we proposed an algorithm for such patients (Figure 8). Given the high cost of 18F-FDG PET and dosimetric considerations, we believe that its use should be limited to patients with positive predictive factors.

A biopsy is unacceptable for many patients with suspected sarcoidosis and uveitis. Therefore, the first International Workshop on Ocular Sarcoidosis (IWOS) published criteria for the diagnosis of intraocular sarcoidosis eleven years ago [148]. These criteria include a combination of suggestive ophthalmological findings and laboratory investigations when a biopsy is not performed or is negative. The IWOS criteria have been retrospectively validated in Japan with a control group consisting mainly of patients with BD or VKH syndrome [172]. Based on a multicentric retrospective review of medical records, including 884 patients in 12 countries, Acharya et al. showed that the 2009 IWOS clinical criteria and the investigational tests had low sensitivities, except for bilateral hilar lymphadenopathy, and that among 264 patients suspected of having sarcoidosis, 97 (37\%) did not met the criteria [173]. To overcome these limitations, the revised IWOS criteria were recently established in an international meeting. The survey and subsequent workshop reached consensus agreements on four criteria which are summarized in Table 3 [171]. The most substantial changes were the addition of 4 systemic investigations: (1) lymphopenia; (2) CD4 alveolar lymphocytosis; (3) parenchymal lung changes consistent with sarcoidosis; and (4) abnormal label uptake on 67-Ga scintigraphy or 18F-FDG PET. A recent Japanese retrospective study showed that the revised IWOS criteria were useful, but could be improved by modifying the criterion of presumed or probable OS [174]. 


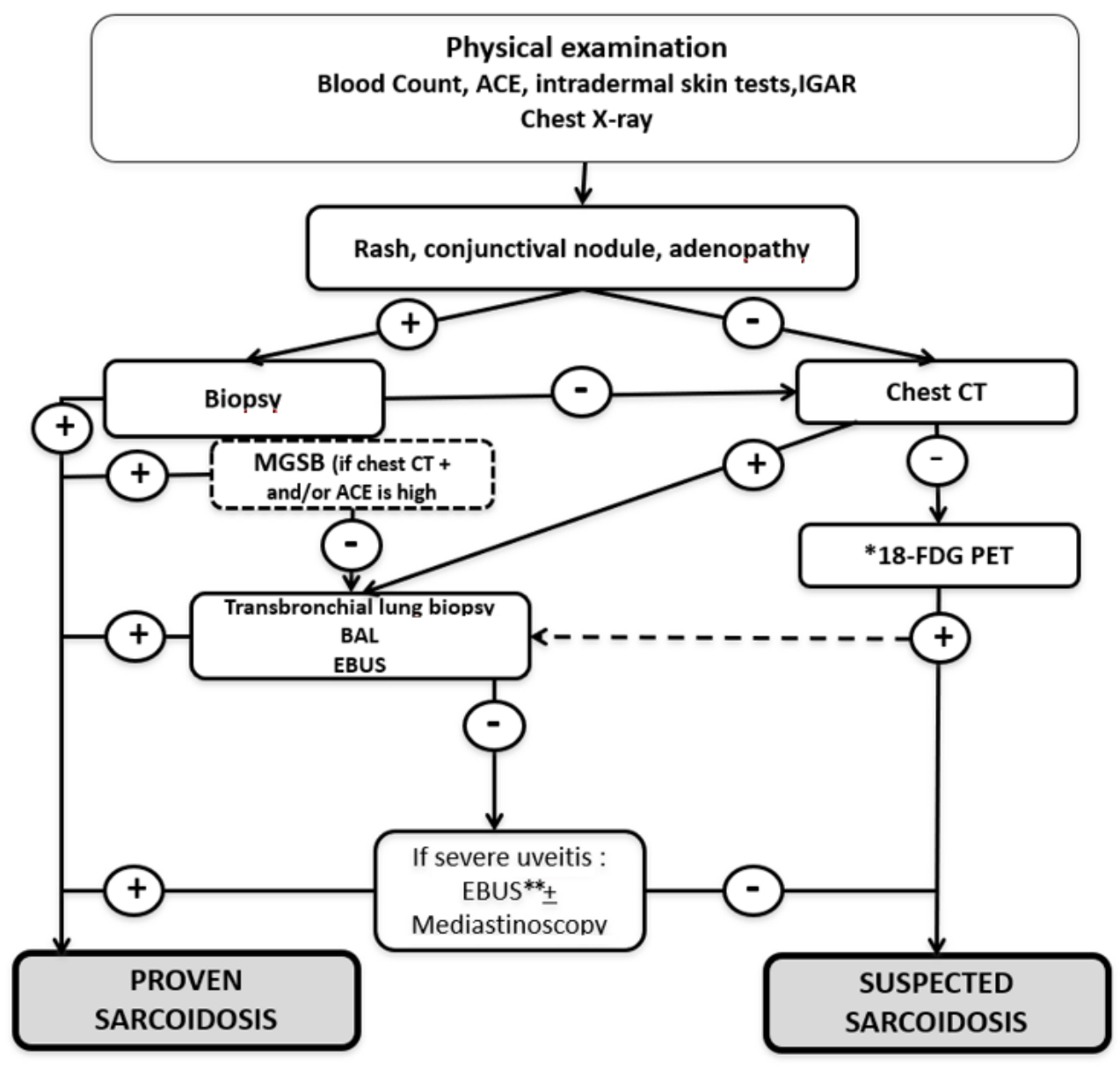

Figure 8. Algorithm to assess uveitis in patients with suspected sarcoidosis (From Sève et al., Sem Resp Crit Care Med, 2020). Abbreviations and notes: ACE: angiotensin converting enzyme; BAL: bronchoalveolar lavage; EBUS: endoscopic ultrasound-guided fine-needle aspiration of intrathoracic nodes; MSGB: minor salivary-gland biopsy; 18F-FDG PET: 18-fluorodeoxyglucose positron-emission tomography. ${ }^{*}$ if old age at uveitis presentation, presence of synechia and an elevated ACE; ${ }^{* *}$ If EBUS not previously performed. The yield of diagnoses from a bronchoalveolar lavage and a trans-bronchoscopic biopsy in patients with an abnormal PET and normal chest CT is unknown. Negative mediastinal lymph-node biopsies from patients with mediastinal lymphadenopathy are, in our experience, exceptional.

Table 3. Revised criteria of International Workshop on Ocular Sarcoidosis (IWOS) for the diagnosis of ocular sarcoidosis (from [171]).

\section{Other causes of granulomatous uveitis must be ruled out}

\section{Intraocular signs suggestive of ocular sarcoidosis}

1. Mutton-fat keratic precipitates(large or small) and/or iris nodules at pupillary margin (Koeppe) or in stroma (Busacca)

2. Trabecular meshwork nodules and/or tent-shaped peripheral anterior synechia

3. Snowballs/strings of pearls vitreous opacities

4. Multiple chorioretinal peripheral lesions (active and/or atrophic)

5 . Nodular and/or segmental periphlebitis ( \pm candle-wax drippings) and/or macroaneurysm in an inflamed eye

6. Optic-disc nodule(s)/granuloma(s) and/or solitary choroidal nodule

7. Bilaterality (assessed by ophthalmological examination including ocular imaging showing subclinical inflammation) 
Table 3. Cont.

\section{Systemic investigation results in suspected ocular sarcoidosis}

1. Bilateral hilar lymphadenopathy on chest X-ray and/or chest computed CT scan

2. Negative tuberculin test in a BCG-vaccinated patient or interferon-gamma releasing assays

3. Elevated serum angiotensin converting-enzyme

4. Elevated serum lysozyme

5. Elevated CD4/CD8 ratio (>3.5) in bronchoalvelar lavage fluid

6. Abnormal label uptake on 67 -gallium scintigraphy or $18 \mathrm{~F}$-fluorodesoxyglucose positron emission tomography imaging

7. Lymphopenia

8. Parenchymal lung changes consistent with sarcoidosis, as determined by pneumologists or radiologists

Diagnostic criteria of ocular sarcoidosis

Diagnostic criteria of ocular sarcoidosis were established in 3 levels of certainty:

- Definite ocular sarcoidosis: diagnosis supported by biopsy with compatible uveitis

- $\quad$ Presumed ocular sarcoidosis: diagnosis not supported by biopsy, but bilateral hilar lymphadenopathy present with two intraocular signs

- $\quad$ Probable ocular sarcoidosis: diagnosis not supported by biopsy and bilateral hilar lymphadenopathy absent, but three intraocular signs and two systemic investigations selected from two to eight are present

\subsubsection{Treatment}

The literature concerning the medical treatment of uveitis in patient with sarcoidosis is full of case reports, uncontrolled studies, and small case series [72]. The treatment of sarcoid uveitis largely follows the general principles of idiopathic uveitis (Figure 9) [71]. Almost all patients required local treatment (steroids) while $45 \%$ to $70 \%$ required systemic treatment, mainly for isolated ocular inflammation [144] and sometimes for concomitant ocular inflammation and active systemic disease [151]. MTX is the most widely used immunosuppressive agent [71]. As with other forms of severe non-infectious uveitis, monoclonal antibodies against TNF- $\alpha$ have been used in sarcoid uveitis [175]. Although one randomized clinical trial with the fusion protein etanercept did not report any improvement [176], several case reports [177] have shown the efficacy of humanized anti-TNF- $\alpha$ monoclonal antibodies for the treatment of refractory ocular sarcoidosis, defined by failure of second-line immunosuppressants to achieve satisfactory disease control [178]. In addition, several case-series have reported the efficacy of infliximab and ADA in ocular sarcoidosis $[179,180]$. In the same way, we reported the efficacy of TNF- $\alpha$ antagonists in 12 of $18(67 \%)$ patients with refractory sarcoid uveitis [181]. Severe adverse events were frequent, mainly infections, requiring anti-TNF- $\alpha$ interruption in $33 \%$ of patients. Overall, TNF- $\alpha$ antagonists appear to be effective in severe and refractory sarcoid uveitis. Their efficacy seems to be temporary and relapses occur in most of these patients within 3 months after treatment discontinuation. In our experience, refractory uveitis in sarcoidosis is unusual (11/301 patients (3\%); unpublished data) and clinicians should first rule out non-compliance, infectious uveitis, or lymphoma before starting infliximab or ADA $[182,183]$. Novel therapeutic approaches have been investigated in refractory sarcoidosis with biologics such as rituximab, tocilizumab, or small molecules, including JAK inhibitors. The medical literature supports their use in refractory sarcoid uveitis in case reports [184-187]. 


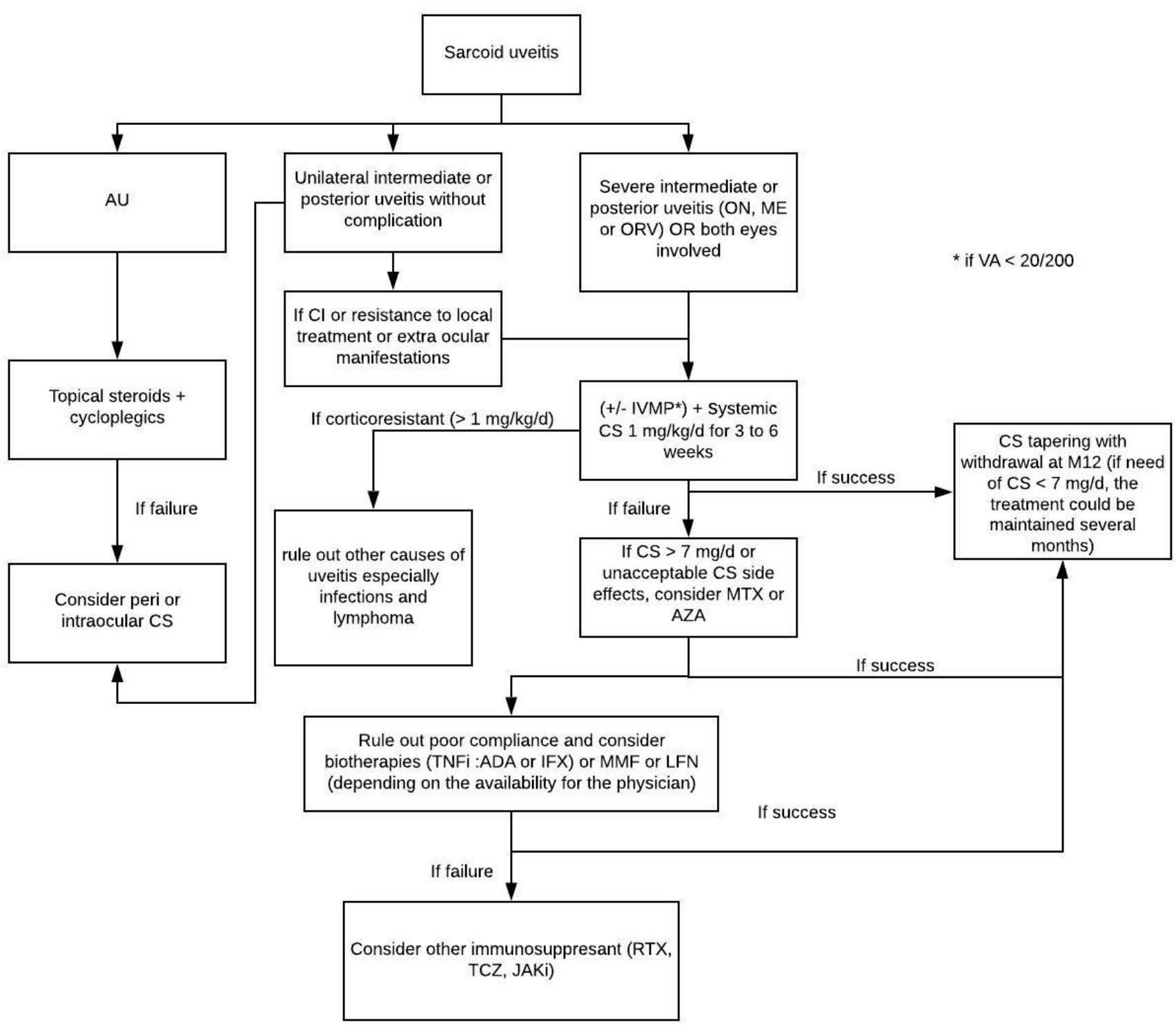

Figure 9. Corticosteroids management in non-infectious uveitis (Sève et al., Sem Resp Crit Care Med, 2020). Abbreviations: AU: anterior uveitis; CS: corticosteroids; ON: optic neuritis; ME: macular edema; ORV: occlusive retinal vasculitis; VA: visual acuity; IVMP: intravenous methylprednisolone pulse; CI: contra indication; TNFi: Tumor Necrosis Factor inhibitor; ADA: adalimumab; IFX: infliximab; MTX: methotrexate; AZA: azathioprine; MMF: mycophenolate mofetil; LFN: leflunomide; RTX: rituximab; TCZ: tocilizumab; JAKi: Janus kinase inhibitor.

\section{Discussion}

In our tertiary center, among 253 patients referred by ophthalmologists for the diagnostic work-up of uveitis in the last two years, 75 (29.6\%) have been diagnosed with Spa, $\mathrm{BD}$, or sarcoidosis. Other diagnosed conditions included HLA-B27 related uveitis (7.9\%), VKH $(1.5 \%)$, multiple sclerosis $(1.5 \%)$, tubulointerstitial nephritis with uveitis $(0.7 \%)$, other inflammatory diseases $(1.1 \%)$, infectious uveitis $(8.5 \%)$, purely ophthalmological entities $(1.6 \%)$, lymphoma $(2.6 \%)$, and uveitis related to drug side effects $(1.1 \%)$. No underlying condition was found in 111 of 253 (44.1\%) patients. In all nine patients with BD, the presence of oral aphtosis together with genital ulcers or skin lesions was sufficient for the diagnosis, which had not been considered before. Similarly, 20 patients with Spa presented unexplained chronic back pain that led to HLA-B27 determination. Among these patients and in case of normal radiograph of the pelvis a sacroiliac MRI was performed [90]. The most frequently identified systemic disease was sarcoidosis $(17.2 \%, n=46)$, with 22 histologically 
proven cases on biopsy: 7 from bronchial samples, 3 from mediastinal lymph nodes, 5 from minor salivary glands, 3 from skin, and 1 from each of peripheral lymph node, thyroid, and stomach. Three patients with normal bronchial samples and normal minor salivary gland biopsy had endobronchial ultrasound-transbronchial needle aspiration of intrathoracic nodes that showed granuloma. Based on Abad's modified criteria, 17 patients had presumed sarcoid uveitis on the basis of either elevated ACE and positive chest CT $(n=11)$ or positive 18F-FDG PET suggestive of sarcoidosis $(n=4)$ and both positive chest CT and 18F-FDG PET $(n=2)$, while 9 patients had possible sarcoidosis (according to the American Thoracic Society guidelines) on the basis of isolated positive 18F-FDG PET $(n=7)$. Only 10 of the 46 patients had an abnormal chest X-ray which was suggestive of sarcoidosis.

To our knowledge, only limited data is available in the medical literature on how the medical history, physical examination, laboratory, and imaging investigations can be useful to make a diagnosis in previously described clinical entities. In the ULISSE study, Parisot et al. found that an etiological diagnosis of uveitis was established for $75.7 \%$ of patients within the first step of the standardized strategy which included a minimal work-up with non-expensive laboratory investigations (CBC, ESR, CRP, tuberculin skin test, syphilis serology, and chest X-ray) and extra diagnostic tests guided by clinical or paraclinical findings. Another $22.8 \%$ of cases were diagnosed after the second or third step which included more complex investigations according to ophthalmological findings. At the end of the third step, extra investigations at the physician's discretion enabled a diagnosis in the remaining cases [29]. Although vitreous measurement of CD4/CD8 ratio seems invasive, one can assume that, in the near future, measures of CD4/CD8 ratios of cellular infiltrates in aqueous humor or cytokine levels in aqueous humor, tears or serum could help diagnose these three inflammatory disorders and stratify patients for tailored treatments [188-190].

Choi et al. recently reported their experience on 179 patients referred to their center with a diagnosis of idiopathic uveitis. They were able to establish a diagnosis in 52 patients $(29 \%)$. Sarcoidosis was the most common diagnosis $(n=19,36.5 \%)$, followed by HLA-B27associated uveitis while one patient had BD, and no underlying condition was found in 127 of 179 patients $(70.9 \%)$ [191].

Our results underscore the need for rapid diagnosis in these fatal pathologies, and for a multidisciplinary approach, in parallel with evaluation by the ophthalmologist.

Author Contributions: Writing-review \& editing, T.E.J., O.L., Y.J., M.G.-V., L.K. and P.S. All authors have read and agreed to the published version of the manuscript.

Funding: This research received no external funding.

Institutional Review Board Statement: This study received approval from the local ethics committee in February 2019 (No 19-31) and was registered on clinicaltrials.gov (NCT 03863782).

Informed Consent Statement: Informed consent was obtained from all subjects involved in the study.

Data Availability Statement: The data presented in this study are available on request from the corresponding author. The data are not publicly available due to privacy concerns.

Acknowledgments: Diagrams created in Lucidchart (on Lucidchart website).

Conflicts of Interest: Laurent Kodjikian declared conflicts of interest from Abbvie, Allergan, Bayer, Novartis, Roche, Théa. Other authors declare no conflict of interests.

\section{References}

1. Prete, M.; Dammacco, R.; Fatone, M.C.; Racanelli, V. Autoimmune uveitis: Clinical, pathogenetic, and therapeutic features. Clin. Exp. Med. 2015, 16, 125-136. [CrossRef] [PubMed]

2. Gritz, D.C. Incidence and prevalence of uveitis in Northern California The Northern California Epidemiology of Uveitis Study. Ophthalmology 2004, 111, 491-500. [CrossRef] [PubMed]

3. Rim, T.H.; Kim, S.S.; Ham, D.-I.; Yu, S.-Y.; Chung, E.J.; Lee, S.C. Incidence and prevalence of uveitis in South Korea: A nationwide cohort study. Br. J. Ophthalmol. 2017, 102, 79-83. [CrossRef] [PubMed]

4. Thorne, J.E.; Suhler, E.; Skup, M.; Tari, S.; Macaulay, D.; Chao, J.; Ganguli, A. Prevalence of Noninfectious Uveitis in the United States. JAMA Ophthalmol. 2016, 134, 1237-1245. [CrossRef] 
5. $\quad$ Dick, A.D.; Rosenbaum, J.T.; Al-Dhibi, H.A.; Belfort, R.; Brézin, A.P.; Chee, S.-P.; Davis, J.L.; Ramanan, A.V.; Sonoda, K.-H.; Carreño, E.; et al. Guidance on Noncorticosteroid Systemic Immunomodulatory Therapy in Noninfectious Uveitis. Ophthalmology 2018, 125, 757-773. [CrossRef]

6. Pirani, V.; Pelliccioni, P.; De Turris, S.; Rosati, A.; Franceschi, A.; Cesari, C.; Nicolai, M.; Mariotti, C.; Turris, D. The Eye as a Window to Systemic Infectious Diseases: Old Enemies, New Imaging. J. Clin. Med. 2019, 8, 1392. [CrossRef]

7. Kitamei, H.; Kitaichi, N.; Namba, K.; Kotake, S.; Goda, C.; Kitamura, M.; Miyazaki, A.; Ohno, S. Clinical features of intraocular inflammation in Hokkaido, Japan. Acta Ophthalmol. 2009, 87, 424-428. [CrossRef]

8. Yang, P.; Zhong, Z.; Du, L.; Li, F.; Chen, Z.; Zhu, Y.; Zhang, W.; Huang, F.; Ye, X.; Su, G.; et al. Prevalence and clinical features of systemic diseases in Chinese patients with uveitis. Br. J. Ophthalmol. 2021, 105, 75-82. [CrossRef]

9. Yalçındă̆, F.N.; Özdal, P.C.; Özyazgan, Y.; Batığlu, F.; Tugal-Tutkun, I. on behalf of the BUST Study Group Demographic and Clinical Characteristics of Uveitis in Turkey: The First National Registry Report. Ocul. Immunol. Inflamm. 2018, 26, 17-26. [CrossRef]

10. Zagora, S.L.; Symes, R.; Yeung, A.; Yates, W.B.; Wakefield, D.; McCluskey, P. Etiology and Clinical Features of Ocular Inflammatory Diseases in a Tertiary Referral Centre in Sydney, Australia. Ocul. Immunol. Inflamm. 2016, 25, 1-8. [CrossRef]

11. Khairallah, M.; Ben Yahia, S.; Ladjimi, A.; Messaoud, R.; Zaouali, S.; Attia, S.; Jenzeri, S.; Jelliti, B. Pattern of uveitis in a referral centre in Tunisia, North Africa. Eye 2006, 21, 33-39. [CrossRef]

12. Sukavatcharin, S.; Kijdaoroong, O.; Lekhanont, K.; Vallipakorn, S.A.-O. Pattern of Uveitis in a Tertiary Ophthalmology Center in Thailand. Ocul. Immunol. Inflamm. 2017, 25, S94-S99. [CrossRef] [PubMed]

13. Biswas, J.; Sitaula, R.K.; Multani, P. Changing uveitis patterns in South India-Comparison between two decades. Indian J. Ophthalmol. 2018, 66, 524-527. [CrossRef] [PubMed]

14. De-La-Torre, A.; López-Castillo, C.A.; Rueda, J.C.; Mantilla, R.D.; Gómez-Marín, J.E.; Anaya, J.-M. Clinical patterns of uveitis in two ophthalmology centres in Bogota, Colombia. Clin. Exp. Ophthalmol. 2009, 37, 458-466. [CrossRef] [PubMed]

15. Chen, E.J.; Bin Ismail, M.A.; Mi, H.; Ho, S.L.; Lim, W.K.; Teoh, S.C.; Agrawal, R. Ocular Autoimmune Systemic Inflammatory Infectious Study (OASIS)—Report 1: Epidemiology and Classification. Ocul. Immunol. Inflamm. 2016, 26, 732-746. [CrossRef]

16. Abad, S.; Seve, P.; Dhote, R.; Brézin, A.-P. Uvéites et médecine interne: Stratégies diagnostique et thérapeutique. Rev. Médecine Interne 2009, 30, 492-500. [CrossRef]

17. Keino, H.; Nakashima, C.; Watanabe, T.; Taki, W.; Hayakawa, R.; Sugitani, A.; Okada, A.A. Frequency and clinical features of intraocular inflammation in Tokyo. Clin. Exp. Ophthalmol. 2009, 37, 595-601. [CrossRef] [PubMed]

18. Bertrand, P.-J.; Jamilloux, Y.; Ecochard, R.; Richard-Colmant, G.; Gerfaud-Valentin, M.; Guillaud, M.; Denis, P.; Kodjikian, L.; Sève, P. Uveitis: Autoimmunity ... and beyond. Autoimmun. Rev. 2019, 18, 102351. [CrossRef] [PubMed]

19. Cunningham, E.T.; Tallstedt, L. Epidemiology of uveitis in a region of southern Sweden. Acta Ophthalmol. 2020, 98, 32-35. [CrossRef]

20. Rothova, A.; Hajjaj, A.; De Hoog, J.; Thiadens, A.A.; Dalm, V.A. Uveitis causes according to immune status of patients. Acta Ophthalmol. 2019, 97, 53-59. [CrossRef] [PubMed]

21. Luca, C.; Aldigeri, R.; Sylvia, M.; Valentina, M.; Fabiana, V.; Marco, C.; Annamaria, S.; Savoldi, L.; Alessandro, D.F.; Lucia, B.; et al. Changes in patterns of uveitis at a tertiary referral center in Northern Italy: Analysis of 990 consecutive cases. Int. Ophthalmol. 2017, 38, 133-142. [CrossRef] [PubMed]

22. Bodaghi, B.; Cassoux, N.; Wechsler, B.; Hannouche, D.; Fardeau, C.; Papo, T.; Huong, D.L.T.; Piette, J.-C.; LeHoang, P. Chronic Severe Uveitis. Medicine 2001, 80, 263-270. [CrossRef] [PubMed]

23. Llorenç, V.; Mesquida, M.; De La Maza, M.S.; Keller, J.; Molins, B.; Espinosa, G.; Hernández, M.V.; Gonzalez-Martin, J.; Adán, A. Epidemiology of uveitis in a Western urban multiethnic population. The challenge of globalization. Acta Ophthalmol. 2015, 93, 561-567. [CrossRef] [PubMed]

24. Jakob, E.; Reuland, M.S.; Mackensen, F.; Harsch, N.; Fleckenstein, M.; Lorenz, H.; Max, R.; Becker, M.D. Uveitis Subtypes in a German Interdisciplinary Uveitis Center-Analysis of 1916 Patients. J. Rheumatol. 2009, 36, 127-136. [CrossRef] [PubMed]

25. Jones, N.P. The Manchester Uveitis Clinic: The First 3000 Patients-Epidemiology and Casemix. Ocul. Immunol. Inflamm. 2013, 23, 118-126. [CrossRef]

26. Oruc, S.; Kaplan, A.D.; Galen, M.; Kaplan, H.J. Uveitis referral pattern in a Midwest University Eye Center. Ocul. Immunol. Inflamm. 2003, 11, 287-298. [CrossRef]

27. Bajwa, A.; Osmanzada, D.; Osmanzada, S.; Khan, I.; Patrie, J.; Wenjun, X.; Reddy, A.K.; Xin, W. Epidemiology of uveitis in the mid-Atlantic United States. Clin. Ophthalmol. 2015, 9, 889-901. [CrossRef]

28. Barisani-Asenbauer, T.; Maca, S.M.; Mejdoubi, L.; Emminger, W.; Machold, K.P.; Auer, H. Uveitis- a rare disease often associated with systemic diseases and infections-A systematic review of 2619 patients. Orphanet J. Rare Dis. 2012, 7, 57. [CrossRef]

29. De Parisot, A.; Kodjikian, L.; Errera, M.-H.; Sedira, N.; Héron, E.; Pérard, L.; Cornut, P.-L.; Schneider, C.; Rivière, S.; Ollé, P.; et al. Randomized Controlled Trial Evaluating a Standardized Strategy for Uveitis Etiologic Diagnosis (ULISSE). Am. J. Ophthalmol. 2017, 178, 176-185. [CrossRef]

30. Testi, I.; Tognon, M.S.; Gupta, V. Ocular Whipple Disease: Report of Three Cases. Ocul. Immunol. Inflamm. 2019, 27, 1117-1120. [CrossRef]

31. Curragh, D.S.; McAvoy, C.E.; Rooney, M.; McLoone, E. Post-streptococcal uveitis syndrome in a Caucasian population: A case series. Eye 2019, 33, 380-384. [CrossRef] [PubMed] 
32. Bettach, E.; Zadok, D.; Weill, Y.; Brosh, K.; Hanhart, J. Bilateral anterior uveitis as a part of a multisystem inflammatory syndrome secondary to COVID-19 infection. J. Med. Virol. 2021, 93, 139-140. [CrossRef] [PubMed]

33. Spadaro, M.; Gerdes, L.A.; Krumbholz, M.; Ertl-Wagner, B.; Thaler, F.S.; Schuh, E.; Metz, I.; Blaschek, A.; Dick, A.; Brück, W.; et al. Autoantibodies to MOG in a distinct subgroup of adult multiple sclerosis. Neurol. Neuroimmunol. Neuroinflammation 2016,3 , e257. [CrossRef] [PubMed]

34. Fousekis, F.S.; Katsanos, A.; Katsanos, K.H.; Christodoulou, D. Ocular manifestations in celiac disease: An overview. Int. Ophthalmol. 2020, 40, 1049-1054. [CrossRef] [PubMed]

35. Bascherini, V.; Granato, C.; Lopalco, G.; Emmi, G.; Vannozzi, L.; Bacherini, D.; Franceschini, R.; Iannone, F.; Salerni, A.; Molinaro, F.; et al. The protean ocular involvement in monogenic autoinflammatory diseases: State of the art. Clin. Rheumatol. 2015, 34, 1171-1180. [CrossRef]

36. Pasquet, F.; Kodjikian, L.; Mura, F.; Riviere, S.; Harroche, J.; Blanc, A.-P.; Chaix, F.; Oksenhendler, E.; Seve, P. For the DEF-I study group Uveitis and Common Variable Immunodeficiency: Data from the DEF-I Study And Literature Review. Ocul. Immunol. Inflamm. 2012, 20, 163-170. [CrossRef]

37. Derzko-Dzulynsky, L. IgG4-related disease in the eye and ocular adnexa. Curr. Opin. Ophthalmol. 2017, 28, 617-622. [CrossRef]

38. Gómez-Mariscal, M.; Oleñik, A.; Arriba-Palomero, P.; García-Cosio, M.; Muñoz-Negrete, F.J. Recurrent Bilateral Anterior Uveitis with Kikuchi-Fujimoto Disease. Ocul. Immunol. Inflamm. 2016, 25, 1-4. [CrossRef]

39. Kato, K.; Namiki, T.; Tokoro, S.; Miura, K.; Yokozeki, H. Histiocytoid Sweet syndrome with ophthalmologic involvements: A novel association with uveitis. J. Dermatol. 2017, 44, 216-217. [CrossRef]

40. Ucar, D.; Kim, J.S.; Bishop, R.J.; Nussenblatt, R.B.; Rao, V.K.; Sen, H.N. Ocular Inflammatory Disorders in Autoimmune Lymphoproliferative Syndrome (ALPS). Ocul. Immunol. Inflamm. 2017, 25, 708-714. [CrossRef]

41. Touhami, S.; Audo, I.; Terrada, C.; Gaudric, A.; LeHoang, P.; Touitou, V.; Bodaghi, B. Neoplasia and intraocular inflammation: From masquerade syndromes to immunotherapy-induced uveitis. Prog. Retin. Eye Res. 2019, 72, 100761. [CrossRef] [PubMed]

42. Cunningham, E.T., Jr.; Moorthy, R.S.; Fraunfelder, F.W.; Zierhut, M. Vaccine-Associated Uveitis. Ocul. Immunol. Inflamm. 2019, 27, 517-520. [CrossRef] [PubMed]

43. Cotte, P.; Pradat, P.; Kodjikian, L.; Jamilloux, Y.; Sève, P. Diagnostic value of lymphopaenia and elevated serum ACE in patients with uveitis. Br. J. Ophthalmol. 2020. [CrossRef] [PubMed]

44. Niederer, R.L.; Al-Janabi, A.; Lightman, S.L.; Tomkins, O. Serum Angiotensin-Converting Enzyme Has a High Negative Predictive Value in the Investigation for Systemic Sarcoidosis. Am. J. Ophthalmol. 2018, 194, 82-87. [CrossRef] [PubMed]

45. Gundlach, E.; Hoffmann, M.M.; Prasse, A.; Heinzelmann, S.; Neß, T. Interleukin-2 Receptor and Angiotensin-Converting Enzyme as Markers for Ocular Sarcoidosis. PLoS ONE 2016, 11, e0147258. [CrossRef] [PubMed]

46. Sève, P.; Cacoub, P.; Bodaghi, B.; Trad, S.; Sellam, J.; Bellocq, D.; Bielefeld, P.; Sène, D.; Kaplanski, G.; Monnet, D.; et al. Uveitis: Diagnostic work-up. A literature review and recommendations from an expert committee. Autoimmun. Rev. 2017, 16, 1254-1264. [CrossRef]

47. Sahin, O.; Ziaei, A.; Karaismailoglu, E.; Taheri, N. The serum angiotensin converting enzyme and lysozyme levels in patients with ocular involvement of autoimmune and infectious diseases. BMC Ophthalmol. 2016, 16, 1-9. [CrossRef]

48. Bennett, D.; Cameli, P.; Lanzarone, N.; Carobene, L.; Bianchi, N.; Fui, A.; Rizzi, L.; Bergantini, L.; Cillis, G.; D’Alessandro, M.; et al. Chitotriosidase: A biomarker of activity and severity in patients with sarcoidosis. Respir. Res. 2020, 21, 1-12. [CrossRef]

49. Dougados, M.; Baeten, D. Spondyloarthritis. Lancet 2011, 377, 2127-2137. [CrossRef]

50. Stolwijk, C.; Van Tubergen, A.; Castillo-Ortiz, J.D.; Boonen, A. Prevalence of extra-articular manifestations in patients with ankylosing spondylitis: A systematic review and meta-analysis. Ann. Rheum. Dis. 2013, 74, 65-73. [CrossRef]

51. Varkas, G.; Vastesaeger, N.; Cypers, H.; Colman, R.; Renson, T.; Van Praet, L.; Carron, P.; Raeman, F.; Devinck, M.; Gyselbrecht, L.; et al. Association of Inflammatory Bowel Disease and Acute Anterior Uveitis, but Not Psoriasis, With Disease Duration in Patients With Axial Spondyloarthritis. Arthritis Rheumatol. 2018, 70, 1588-1596. [CrossRef] [PubMed]

52. De Winter, J.J.; Van Mens, L.J.; Van Der Heijde, D.; Landewé, R.; Baeten, D.L. Prevalence of peripheral and extra-articular disease in ankylosing spondylitis versus non-radiographic axial spondyloarthritis: A meta-analysis. Arthritis Res. 2016, 18, 1-11. [CrossRef]

53. Arepalli, S.; Rosenbaum, J.T. The use of biologics for uveitis associated with spondyloarthritis. Curr. Opin. Rheumatol. 2019, 31, 349-354. [CrossRef]

54. Biedermann, L.; Renz, L.; Fournier, N.; Rossel, J.-B.; Butter, M.; Bluemel, S.; Vavricka, S.R.; Rogler, G.; Scharl, M.; Anderegg, C.; et al. Uveitis manifestations in patients of the Swiss Inflammatory Bowel Disease Cohort Study. Ther. Adv. Gastroenterol. 2019, 12, 175628481986514. [CrossRef] [PubMed]

55. Sharma, S.M.; Jackson, D. Uveitis in the Spondyloarthopathies. Best Pract. Res. Clin. Rheumatol. 2017, 31, 846-862. [CrossRef]

56. Bengtsson, K.; Forsblad-D’Elia, H.; Deminger, A.; Klingberg, E.; Dehlin, M.; Exarchou, S.; Lindström, U.; Askling, J.; Jacobsson, L.T.H. Incidence of extra-articular manifestations in ankylosing spondylitis, psoriatic arthritis and undifferentiated spondyloarthritis: Results from a national register-based cohort study. Rheumatology 2020, keaa692. [CrossRef]

57. Bacchiega, A.B.S.; Balbi, G.G.M.; Ochtrop, M.L.G.; De Andrade, F.A.; Levy, R.A.; Baraliakos, X. Ocular involvement in patients with spondyloarthritis. Rheumatology 2017, 56, 2060-2067. [CrossRef]

58. Rosenbaum, J.T.; Dick, A.D. The Eyes Have it. Arthritis Rheumatol. 2018, 70, 1533-1543. [CrossRef] 
59. International Team for the Revision of the International Criteria for Behçet's Disease (ITR-ICBD); Davatchi, F.; Assaadkhalil, S.H.; Calamia, K.T.; E Crook, J.; Sadeghiabdollahi, B.; Schirmer, M.; Tzellos, T.; Zouboulis, C.C.; Akhlagi, M.; et al. The International Criteria for Behçet's Disease (ICBD): A collaborative study of 27 countries on the sensitivity and specificity of the new criteria. J. Eur. Acad. Dermatol. Venereol. 2013, 28, 338-347. [CrossRef]

60. Yurdakul, S.; Günaydin, I.; Tüzün, Y.; Tankurt, N.; Pazarli, H.; Ozyazgan, Y.; Yazici, H. The prevalence of Behçet's syndrome in a rural area in northern Turkey. J. Rheumatol. 1988, 15, 820-822.

61. A Chamberlain, M. Behcet's syndrome in 32 patients in Yorkshire. Ann. Rheum. Dis. 1977, 36, 491-499. [CrossRef] [PubMed]

62. Davatchi, F. Behcet's disease. Int. J. Rheum. Dis. 2014, 17, 355-357. [CrossRef] [PubMed]

63. Internationalstudygroupforbehc Criteria for diagnosis of Behcet's disease. Lancet 1990, 335. [CrossRef]

64. Khairallah, M.; Accorinti, M.; Muccioli, C.; Kahloun, R.; Kempen, J.H. Epidemiology of Behçet Disease. Ocul. Immunol. Inflamm. 2012, 20, 324-335. [CrossRef]

65. Ozyazgan, Y.; Ucar, D.; Hatemi, G.; Yazici, Y. Ocular Involvement of Behçet's Syndrome: A Comprehensive Review. Clin. Rev. Allergy Immunol. 2014, 49, 298-306. [CrossRef]

66. Davatchi, F.; Chams-Davatchi, C.; Shams, H.; Shahram, F.; Nadji, A.; Akhlaghi, M.; Faezi, T.; Ghodsi, Z.; Abdollahi, B.S.; Ashofteh, F.; et al. Behcet's disease: Epidemiology, clinical manifestations, and diagnosis. Expert Rev. Clin. Immunol. 2016, $13,57-65$. [CrossRef]

67. Sakthivel, P.; Bruder, D. Mechanism of granuloma formation in sarcoidosis. Curr. Opin. Hematol. 2017, 24, 59-65. [CrossRef]

68. Costabel, U.; Hunninghake, G.W. on behalf of the Sarcoidosis Statement Committee ATS/ERS/WASOG statement on sarcoidosis. Eur. Respir. J. 1999, 14, 735-737. [CrossRef]

69. Arkema, E.V.; Cozier, Y.C. Epidemiology of sarcoidosis: Current findings and future directions. Ther. Adv. Chronic Dis. 2018, 9 , 227-240. [CrossRef]

70. Pereira, C.A.; Dornfeld, M.C.; Baughman, R.; Judson, M.A. Clinical phenotypes in sarcoidosis. Curr. Opin. Pulm. Med. 2014, 20, 496-502. [CrossRef]

71. Sève, P.; Jamilloux, Y.; Tilikete, C.; Gerfaud-Valentin, M.; Kodjikian, L.; El Jammal, T. Ocular Sarcoidosis. Semin. Respir. Crit. Care Med. 2020, 41, 673-688. [CrossRef] [PubMed]

72. Jamilloux, Y.; Kodjikian, L.; Broussolle, C.; Sève, P. Sarcoidosis and uveitis. Autoimmun. Rev. 2014, 13, 840-849. [CrossRef] [PubMed]

73. Dammacco, R.; Biswas, J.; Kivelä, T.T.; Zito, F.A.; Leone, P.; Mavilio, A.; Sisto, D.; Alessio, G.; Dammacco, F. Ocular sarcoidosis: Clinical experience and recent pathogenetic and therapeutic advancements. Int. Ophthalmol. 2020, 40, 3453-3467. [CrossRef] [PubMed]

74. Brewerton, D.; Nicholls, A.; Caffrey, M.; Walters, D.; James, D. Acute Anterior Uveitis and HLA-B27. Lancet 1973, 302, 994-996. [CrossRef]

75. Chang, J.H.; McCluskey, P.J.; Wakefield, D. Acute Anterior Uveitis and HLA-B27. Surv. Ophthalmol. 2005, 50, 364-388. [CrossRef] [PubMed]

76. Kopplin, L.J.; Mount, G.; Suhler, E.B. Review for Disease of the Year: Epidemiology of HLA-B27 Associated Ocular Disorders. Ocul. Immunol. Inflamm. 2016, 24, 470-475. [CrossRef]

77. Zeboulon, N.; Dougados, M.; Gossec, L. Prevalence and characteristics of uveitis in the spondyloarthropathies: A systematic literature review. Ann. Rheum. Dis. 2008, 67, 955-959. [CrossRef]

78. Kim, M.; Sim, Y.S.; Choi, S.Y.; Park, Y.-H. Potential predictors for frequent relapse in human leukocyte antigen-B27-associated uveitis. Graefes Arch. Clin. Exp. Ophthalmol. 2018, 256, 1543-1549. [CrossRef]

79. Suhler, E.B.; Martin, T.M.; Rosenbaum, J.T. HLA-B27 Associated uveitis: Overview and current perspectives. Curr. Opin. Ophthalmol. 2003, 14, 378-383. [CrossRef]

80. Monnet, D. Ophthalmic findings and frequency of extraocular manifestations in patients with HLA-B27 uveitis*1A study of 175 cases. Ophthalmology 2004, 111, 802-809. [CrossRef]

81. Pathanapitoon, K.; Dodds, E.M.; Cunningham, E.T.; Rothova, A. Clinical Spectrum of HLA-B27-Associated Ocular Inflammation. Ocul. Immunol. Inflamm. 2017, 25, 569-576. [CrossRef] [PubMed]

82. Chung, Y.; Liao, H.; Lin, K.; Lin, Y.; Chou, C.; Chen, C.; Tsai, C. Prevalence of spondyloarthritis in 504 Chinese patients with HLA-B27-Associated acute anterior uveitis. Scand. J. Rheumatol. 2009, 38, 84-90. [CrossRef] [PubMed]

83. Loh, A.R.; Acharya, N.R. Incidence Rates and Risk Factors for Ocular Complications and Vision Loss in HLA-B27-Associated Uveitis. Am. J. Ophthalmol. 2010, 150, 534-542. [CrossRef]

84. Huhtinen, M. HLA-B27 typing in the categorisation of uveitis in a HLA-B27 rich population. Br. J. Ophthalmol. 2000, 84, 413-416. [CrossRef] [PubMed]

85. El-Shabrawi, Y.; Wegscheider, B.J.; Weger, M.; Renner, W.; Posch, U.; Ulrich, S.; Ardjomand, N.; Hermann, J. Polymorphisms within the Tumor Necrosis Factor- $\alpha$ Promoter Region in Patients with HLA-B27-Associated Uveitis. Ophthalmology 2006, 113, 695-700. [CrossRef]

86. Lindner, E.; Steinwender, G.; Plainer, S.; Poeschl, E.M.; Weger, M.; Ardjomand, N.; Renner, W.; El-Shabrawi, Y. Role of IL-10 gene polymorphisms in intermediate and HLA-B27-associated uveitis. Acta Ophthalmol. 2013, 91, e415-e417. [CrossRef] 
87. Steinwender, G.; Lindner, E.; Weger, M.; Plainer, S.; Renner, W.; Ardjomand, N.; El-Shabrawi, Y. Association between Polymorphism of the Vitamin D Metabolism Gene CYP27B1 and HLA-B27-Associated Uveitis. Is a State of Relative Immunodeficiency Pathogenic in HLA-B27-Positive Uveitis? PLoS ONE 2013, 8, e62244. [CrossRef]

88. Huang, X.-F.; Li, Z.; De Guzman, E.; Robinson, P.; Gensler, L.; Ward, M.M.; Rahbar, M.H.; Lee, M.; Weisman, M.H.; Macfarlane, G.J.; et al. Genomewide Association Study of Acute Anterior Uveitis Identifies New Susceptibility Loci. Investig. Opthalmol. Vis. Sci. 2020, 61, 3. [CrossRef]

89. Lu, M.-C.; Hsu, B.-B.; Koo, M.; Lai, N.-S. Higher risk of incident ankylosing spondylitis in patients with uveitis: A secondary cohort analysis of a nationwide, population-based health claims database. Scand. J. Rheumatol. 2017, 46, 468-473. [CrossRef]

90. Wach, J.; Maucort-Boulch, D.; Kodjikian, L.; Iwaz, J.; Broussolle, C.; Sève, P. Acute anterior uveitis and undiagnosed spondyloarthritis: Usefulness of Berlin criteria. Graefes Arch. Clin. Exp. Ophthalmol. 2015, 253, 115-120. [CrossRef]

91. Haroon, M.; O’Rourke, M.; Ramasamy, P.; Murphy, C.C.; Fitzgerald, O. A novel evidence-based detection of undiagnosed spondyloarthritis in patients presenting with acute anterior uveitis: The DUET (Dublin Uveitis Evaluation Tool). Ann. Rheum. Dis. 2015, 74, 1990-1995. [CrossRef] [PubMed]

92. Oliveira, T.L.; Maksymowych, W.P.; Lambert, R.G.; Muccioli, C.; Fernandes, A.R.; Pinheiro, M.M. Sacroiliac Joint Magnetic Resonance Imaging in Asymptomatic Patients with Recurrent Acute Anterior Uveitis: A Proof-of-concept Study. J. Rheumatol. 2017, 44, 1833-1840. [CrossRef] [PubMed]

93. Muñoz-Fernández, S.; Hidalgo, V.; Fernández-Melón, J.; Schlincker, A.; Bonilla, G.; Ruiz-Sancho, D.; Fonseca, A.; Gijón-Baños, J.; Martín-Mola, E. Sulfasalazine reduces the number of flares of acute anterior uveitis over a one-year period. J. Rheumatol. 2003, 30, 1277-1279. [PubMed]

94. Benitez-Del-Castillo, J.M.; Garcia-Sanchez, J.; Iradier, T.; Bañares, A. Sulfasalazine in the prevention of anterior uveitis associated with ankylosing spondylitis. Eye 2000, 14, 340-343. [CrossRef] [PubMed]

95. Muñoz-Fernández, S.; García-Aparicio, A.M.; Hidalgo, M.V.; Platero, M.; Schlincker, A.; Bascones, M.L.; Pombo, M.; Morente, P.; Sanpedro, J.; Martín-Mola, E. Methotrexate: An option for preventing the recurrence of acute anterior uveitis. Eye 2008, 23, 1130-1133. [CrossRef]

96. Zu Hoerste, M.M.; Walscheid, K.; Tappeiner, C.; Zurek-Imhoff, B.; Heinz, C.; Heiligenhaus, A. The effect of methotrexate and sulfasalazine on the course of HLA-B27-positive anterior uveitis: Results from a retrospective cohort study. Graefes Arch. Clin. Exp. Ophthalmol. 2018, 256, 1985-1992. [CrossRef] [PubMed]

97. Saadoun, D.; Bodaghi, B.; Bienvenu, B.; Wechsler, B.; Sene, D.; Trad, S.; Abad, S.; Cacoub, P.; Kodjikian, L.; Sève, P. Biotherapies in inflammatory ocular disorders: Interferons, immunoglobulins, monoclonal antibodies. Autoimmun. Rev. 2013, 12, 774-783. [CrossRef]

98. Braun, J.; Baraliakos, X.; Listing, J.; Sieper, J. Decreased incidence of anterior uveitis in patients with ankylosing spondylitis treated with the anti-tumor necrosis factor agents infliximab and etanercept. Arthritis Rheum. 2005, 52, 2447-2451. [CrossRef]

99. Rudwaleit, M.; Rødevand, E.; Holck, P.; Vanhoof, J.; Kron, M.; Kary, S.; Kupper, H. Adalimumab effectively reduces the rate of anterior uveitis flares in patients with active ankylosing spondylitis: Results of a prospective open-label study. Ann. Rheum. Dis. 2008, 68, 696-701. [CrossRef]

100. Lie, E.; Lindström, U.; Zverkova-Sandström, T.; Olsen, I.C.; Forsblad-D’Elia, H.; Askling, J.; Kapetanovic, M.C.; Kristensen, L.E.; Jacobsson, L.T.H. Tumour necrosis factor inhibitor treatment and occurrence of anterior uveitis in ankylosing spondylitis: Results from the Swedish biologics register. Ann. Rheum. Dis. 2017, 76, 1515-1521. [CrossRef]

101. Van Bentum, R.E.; Heslinga, S.C.; Nurmohamed, M.T.; Gerards, A.H.; Griep, E.N.; Koehorst, C.B.; Kok, M.R.; Schilder, A.M.; Verhoef, M.; E Van Der Horst-Bruinsma, I. Reduced Occurrence Rate of Acute Anterior Uveitis in Ankylosing Spondylitis Treated with Golimumab-The GO-EASY Study. J. Rheumatol. 2018, 46, 153-159. [CrossRef] [PubMed]

102. Wendling, D.; Paccou, J.; Berthelot, J.-M.; Flipo, R.-M.; Guillaume-Czitrom, S.; Prati, C.; Dernis, E.; Direz, G.; Ferrazzi, V.; Ristori, J.-M. New Onset of Uveitis During Anti-Tumor Necrosis Factor Treatment for Rheumatic Diseases. Semin. Arthritis Rheum. 2011, 41, 503-510. [CrossRef] [PubMed]

103. Gaujoux-Viala, C.; Giampietro, C.; Gaujoux, T.; Ea, H.-K.; Prati, C.; Orcel, P.; Wendling, D.; Lioté, F. Scleritis: A Paradoxical Effect of Etanercept? Etanercept-associated Inflammatory Eye Disease. J. Rheumatol. 2011, 39, 233-239. [CrossRef] [PubMed]

104. Lim, L.L.; Fraunfelder, F.W.; Rosenbaum, J.T. Do tumor necrosis factor inhibitors cause uveitis? A registry-based study. Arthritis Rheum. 2007, 56, 3248-3252. [CrossRef] [PubMed]

105. Lindström, U. Comparison of Anterior Uveitis Occurrence During Treatment with Secukinumab, Adalimumab, Infliximab and Etanercept in Spondyloarthritis. Ann. Rheum. Dis. 2020, 79. [CrossRef]

106. Van Der Heijde, D.; Ramiro, S.; Landewé, R.; Baraliakos, X.; Bosch, F.V.D.; Sepriano, A.; Regel, A.; Ciurea, A.; Dagfinrud, H.; Dougados, M.; et al. 2016 update of the ASAS-EULAR management recommendations for axial spondyloarthritis. Ann. Rheum. Dis. 2017, 76, 978-991. [CrossRef]

107. Sève, P.; Varron, L.; Broussolle, C.; Denis, P.; Kodjikian, L. Sarcoid-related Uveitis Occurring During Adalimumab Therapy. Ocul. Immunol. Inflamm. 2011, 20, 59-60. [CrossRef]

108. Dubinsky, M.C.; Cross, R.K.; Sandborn, W.J.; Long, M.; Song, X.; Shi, N.; Ding, Y.; Eichner, S.; Pappalardo, B.; Ganguli, A.; et al. Extraintestinal Manifestations in Vedolizumab and Anti-TNF-Treated Patients With Inflammatory Bowel Disease. Inflamm. Bowel Dis. 2018, 24, 1876-1882. [CrossRef] 
109. Bouzid, N.; Jamilloux, Y.; Chapurlat, R.; Pradat, P.; De Parisot, A.; Kodjikian, L.; Sève, P. Impact of systemic treatments on the course of HLA-B27-associated uveitis: A retrospective study of 101 patients. PLoS ONE 2020, 15, e0230560. [CrossRef]

110. Zhong, Z.; Su, G.; Kijlstra, A.; Yang, P. Activation of the interleukin-23/interleukin-17 signalling pathway in autoinflammatory and autoimmune uveitis. Prog. Retin. Eye Res. 2020, 100866, 100866. [CrossRef]

111. Deodhar, A.; Miceli-Richard, C.; Baraliakos, X.; Marzo-Ortega, H.; Gladman, D.D.; Blanco, R.; Das Gupta, A.; Martin, R.; Safi, J.; Porter, B.; et al. Incidence of Uveitis in Secukinumab-treated Patients With Ankylosing Spondylitis: Pooled Data Analysis From Three Phase 3 Studies. ACR Open Rheumatol. 2020, 2, 294-299. [CrossRef] [PubMed]

112. Van Der Heijde, D.; Gladman, D.D.; Kishimoto, M.; Okada, M.; Rathmann, S.S.; Moriarty, S.R.; Shuler, C.L.; Carlier, H.; Benichou, O.; Yi, E. Efficacy and Safety of Ixekizumab in Patients with Active Psoriatic Arthritis: 52-week Results from a Phase III Study (SPIRIT-P1). J. Rheumatol. 2017, 45, 367-377. [CrossRef] [PubMed]

113. Saadoun, D.; Weschler, B. Behçet's Disease. Orphanet. J. Rare Dis. 2012, 7. [CrossRef]

114. Tugal-Tutkun, I.; Onal, S.; Altan-Yaycioglu, R.; Altunbas, H.H.; Urgancioglu, M. Uveitis in Behçet disease: An analysis of 880 patients. Am. J. Ophthalmol. 2004, 138, 373-380. [CrossRef] [PubMed]

115. Taylor, S.R.; Singh, J.; Menezo, V.; Wakefield, D.; McCluskey, P.; Lightman, S. Behçet Disease: Visual Prognosis and Factors Influencing the Development of Visual Loss. Am. J. Ophthalmol. 2011, 152, 1059-1066. [CrossRef]

116. Takeuchi, M.; Hokama, H.; Tsukahara, R.; Kezuka, T.; Goto, H.; Sakai, J.-I.; Usui, M. Risk and prognostic factors of poor visual outcome in Behcet's disease with ocular involvement. Graefes Arch. Clin. Exp. Ophthalmol. 2005, 243, 1147-1152. [CrossRef]

117. Accorinti, M.; Pesci, F.R.; Pirraglia, M.P.; Abicca, I.; Pivetti-Pezzi, P. Ocular Behçet's Disease: Changing Patterns Over Time, Complications and Long-Term Visual Prognosis. Ocul. Immunol. Inflamm. 2016, 25, 29-36. [CrossRef]

118. El Latif, E.A.; Galal, M.A.K.F.; A Tawfik, M.; Elmoddather, M.; Nooreldin, A.; Yousef, H.S. Pattern of Uveitis Associated with Behçet's Disease in an Egyptian Cohort. Clin. Ophthalmol. 2020, 14, 4005-4014. [CrossRef]

119. Davatchi, F.; Abdollahi, B.S.; Chams-Davatchi, C.; Shahram, F.; Nadji, A.; Shams, H.; Faezi, T.; Akhlaghi, M.; Ashofteh, F.; Mataji, M.; et al. Validation of the revised International Criteria for Behcet's Disease (ICBD) in Iran. Clin. Rheumatol. 2013, 34, 315-320. [CrossRef]

120. Tugal-Tutkun, I.; Onal, S.; Stanford, M.; Akman, M.; Twisk, J.W.; Boers, M.; Oray, M.; Özdal, P.Ç.; Kadayifcilar, S.; Amer, R.; et al. An Algorithm for the Diagnosis of Behçet Disease Uveitis in Adults. Ocul. Immunol. Inflamm. 2020, 1-10. [CrossRef]

121. Hatemi, G.; Christensen, R.; Bang, D.; Bodaghi, B.; Celik, A.F.; Fortune, F.; Gaudric, J.; Gül, A.; Kötter, I.; Leccese, P.; et al. 2018 update of the EULAR recommendations for the management of Behçet's syndrome. Ann. Rheum. Dis. 2018, 77, 808-818. [CrossRef] [PubMed]

122. Karada ̆̆, Ö.; Bolek, E.C. Management of Behcet's syndrome. Rheumatology 2020, 59, iii108-iii117. [CrossRef] [PubMed]

123. Akman-Demir, G.; Ayranci, O.; Kurtuncu, M.; Vanli, E.N.; Mutlu, M.; Tugal-Tutkun, I. Cyclosporine for Behçet's uveitis: Is it associated with an increased risk of neurological involvement? Clin. Exp. Rheumatol. 2008, $26,7$.

124. Saadoun, D.; Wechsler, B.; Terrada, C.; Hajage, D.; Huong, D.L.T.; Resche-Rigon, M.; Cassoux, N.; Le Hoang, P.; Amoura, Z.; Bodaghi, B.; et al. Azathioprine in severe uveitis of Behçet's disease. Arthritis Rheum. 2010, 62, 1733-1738. [CrossRef]

125. Ohno, S.; Umebayashi, I.; Matsukawa, M.; Goto, T.; Yano, T. Safety and efficacy of infliximab in the treatment of refractory uveoretinitis in Behçet's disease: A large-scale, long-term postmarketing surveillance in Japan. Arthritis Res. 2019, 21, 2. [CrossRef]

126. Tugal-Tutkun, I.; Özdal, P. Çakar Behçet's disease uveitis: Is there a need for new emerging drugs? Expert Opin. Emerg. Drugs 2020, 25, 531-547. [CrossRef]

127. Atienza-Mateo, B.; Martín-Varillas, J.L.; Calvo-Río, V.; Demetrio-Pablo, R.; Beltrán, E.; Sánchez-Bursón, J.; Mesquida, M.; Adan, A.; Hernández, M.V.; Hernández-Garfella, M.; et al. Comparative Study of Infliximab Versus Adalimumab in Refractory Uveitis due to Behçet's Disease: National Multicenter Study of 177 Cases. Arthritis Rheumatol. 2019, 71, 2081-2089. [CrossRef]

128. Ozguler, Y.; Leccese, P.; Christensen, R.; Esatoglu, S.N.; Bang, D.; Bodaghi, B.; Çelik, A.F.; Fortune, F.; Gaudric, J.; Gül, A.; et al. Management of major organ involvement of Behçet's syndrome: A systematic review for update of the EULAR recommendations. Rheumatology 2018, 57, 2200-2212. [CrossRef]

129. Diwo, E.; Gueudry, J.; Saadoun, D.; Weschler, B.; LeHoang, P.; Bodaghi, B. Long-term Efficacy of Interferon in Severe Uveitis Associated with Behçet Disease. Ocul. Immunol. Inflamm. 2017, 25, 76-84. [CrossRef]

130. Celiker, H.; Kazokoglu, H.; Direskeneli, H. Factors Affecting Relapse and Remission in Behçet's Uveitis Treated with Interferon Alpha2a. J. Ocul. Pharmacol. Ther. 2019, 35, 58-65. [CrossRef]

131. Yalçindag, N.; Köse, H.C. Comparison of the Treatment Results for Behçet Uveitis in Patients Treated with Infliximab and Interferon. Ocul. Immunol. Inflamm. 2020, 28, 305-314. [CrossRef] [PubMed]

132. Bettiol, A.; Silvestri, E.; Di Scala, G.; Amedei, A.; Becatti, M.; Fiorillo, C.; Lopalco, G.; Salvarani, C.; Cantarini, L.; Soriano, A.; et al. The right place of interleukin-1 inhibitors in the treatment of Behçet's syndrome: A systematic review. Rheumatol. Int. 2019, 39, 971-990. [CrossRef] [PubMed]

133. Tugal-Tutkun, I.; Pavesio, C.; De Cordoue, A.; Bernard-Poenaru, O.; Gül, A. Use of Gevokizumab in Patients with Behçet's Disease Uveitis: An International, Randomized, Double-Masked, Placebo-Controlled Study and Open-Label Extension Study. Ocul. Immunol. Inflamm. 2018, 26, 1023-1033. [CrossRef] [PubMed]

134. Fabiani, C.; Vitale, A.; Emmi, G.; Lopalco, G.; Vannozzi, L.; Guerriero, S.; Gentileschi, S.; Bacherini, D.; Franceschini, R.; Frediani, B.; et al. Interleukin (IL)-1 inhibition with anakinra and canakinumab in Behçet's disease-related uveitis: A multicenter retrospective observational study. Clin. Rheumatol. 2017, 36, 191-197. [CrossRef] [PubMed] 
135. Lightman, S.; Taylor, S.R.J.; Bunce, C.; Longhurst, H.; Lynn, W.; Moots, R.; Stanford, M.; Tomkins-Netzer, O.; Yang, D.; Calder, V.L.; et al. Pegylated interferon- $\alpha-2 b$ reduces corticosteroid requirement in patients with Behçet's disease with upregulation of circulating regulatory T cells and reduction of Th17. Ann. Rheum. Dis. 2014, 74, 1138-1144. [CrossRef] [PubMed]

136. Buggage, R.R.; Levy-Clarke, G.; Sen, H.N.; Ursea, R.; Srivastava, S.K.; Suhler, E.B.; Altemare, C.; Velez, G.; Ragheb, J.; Chan, C.-C.; et al. A Double-masked, Randomized Study to Investigate the Safety and Efficacy of Daclizumab to Treat the Ocular Complications Related to Behçet's Disease. Ocul. Immunol. Inflamm. 2007, 15, 63-70. [CrossRef] [PubMed]

137. Dick, A.D.; Tugal-Tutkun, I.; Foster, S.; Zierhut, M.; Liew, S.M.; Bezlyak, V.; Androudi, S. Secukinumab in the Treatment of Noninfectious Uveitis: Results of Three Randomized, Controlled Clinical Trials. Ophthalmology 2013, 120, 777-787. [CrossRef] [PubMed]

138. Davatchi, F.; Shams, H.; Rezaipoor, M.; Abdollahi, B.S.; Shahram, F.; Nadji, A.; Chams-Davatchi, C.; Akhlaghi, M.; Faezi, T.; Naderi, N. Rituximab in intractable ocular lesions of Behcet's disease; randomized single-blind control study (pilot study). Int. J. Rheum. Dis. 2010, 13, 246-252. [CrossRef]

139. Martín-Varillas, J.L.; Calvo-Río, V.; Beltrán, E.; Sánchez-Bursón, J.; Mesquida, M.; Adán, A.; Hernandez, V.; Garfella, M.H.; Pascual, E.V.; Martínez-Costa, L.; et al. Successful Optimization of Adalimumab Therapy in Refractory Uveitis Due to Behçet's Disease. Ophthalmology 2018, 125, 1444-1451. [CrossRef]

140. Pichi, F.; Smith, S.D.; Neri, P.; Woodstock, E.; Hay, S.; Parrulli, S.; Corvi, F.; Mapelli, C.; Invernizzi, A. Choroidal Granulomas Visualized by Swept-Source Optical Coherence Tomography Angiography. Retina 2020. [CrossRef]

141. Coulon, C.; Kodjikian, L.; Rochepeau, C.; Perard, L.; Jardel, S.; Burillon, C.; Broussolle, C.; Jamilloux, Y.; Sève, P. Ethnicity and association with ocular, systemic manifestations and prognosis in 194 patients with sarcoid uveitis. Graefe's Arch. Clin. Exp. Ophthalmol. 2019, 257, 2495-2503. [CrossRef] [PubMed]

142. Birnbaum, A.D.; French, D.D.; Mirsaeidi, M.; Wehrli, S. Sarcoidosis in the National Veteran Population. Ophthalmology 2015, 122, 934-938. [CrossRef] [PubMed]

143. Pasadhika, S.; Rosenbaum, J.T. Ocular Sarcoidosis. Clin. Chest Med. 2015, 36, 669-683. [CrossRef] [PubMed]

144. Ma, S.P.; Rogers, S.L.; Hall, A.J.; Hodgson, L.; Brennan, J.; Stawell, R.J.; Lim, L.L. Sarcoidosis-related Uveitis: Clinical Presentation, Disease Course, and Rates of Systemic Disease Progression After Uveitis Diagnosis. Am. J. Ophthalmol. 2019, 198, 30-36. [CrossRef] [PubMed]

145. Zaidi, A.A.; Ying, G.-S.; Daniel, E.; Gangaputra, S.; Rosenbaum, J.T.; Suhler, E.B.; Thorne, J.E.; Foster, C.S.; Jabs, D.A.; Levy-Clarke, G.A.; et al. Hypopyon in Patients with Uveitis. Ophthalmology 2010, 117, 366-372. [CrossRef]

146. Evans, M.; Sharma, O.; LaBree, L.; Smith, R.E.; Rao, N.A. Differences in Clinical Findings between Caucasians and African Americans with Biopsy-Proven Sarcoidosis. Ophthalmology 2007, 114, 325-333. [CrossRef]

147. Neß, T.; Böhringer, D.; Heinzelmann, S. Intermediate uveitis: Pattern of etiology, complications, treatment and outcome in a tertiary academic center. Orphanet J. Rare Dis. 2017, 12, 1-7. [CrossRef]

148. Herbort, C.P.; A Rao, N.; Mochizuki, M.; The Members of The Scientific members of Scientific Committee of First International Workshop on Ocular Sarcoidosis. International Criteria for the Diagnosis of Ocular Sarcoidosis: Results of the First International Workshop on Ocular Sarcoidosis (IWOS). Ocul. Immunol. Inflamm. 2009, 17, 160-169. [CrossRef]

149. Rothova, A. Ocular involvement in sarcoidosis. Br. J. Ophthalmol. 2000, 84, 110-116. [CrossRef]

150. Kluger, N. Tattoo-associated uveitis with or without systemic sarcoidosis: A comparative review of the literature. J. Eur. Acad. Dermatol. Venereol. 2018, 32, 1852-1861. [CrossRef]

151. Rochepeau, C.; Jamilloux, Y.; Kerever, S.; Febvay, C.; Perard, L.; Broussolle, C.; Burillon, C.; Kodjikian, L.; Seve, P. Long-term visual and systemic prognoses of 83 cases of biopsy-proven sarcoid uveitis. Br. J. Ophthalmol. 2016, 101, 856-861. [CrossRef] [PubMed]

152. Edelsten, C.; Pearson, A.; Joynes, E.; Stanford, M.R.; Graham, E.M. The ocular and systemic prognosis of patients presenting with sarcoid uveitis. Eye 1999, 13, 748-753. [CrossRef] [PubMed]

153. Han, Y.S.; Rivera-Grana, E.; Salek, S.; Rosenbaum, J.T. Distinguishing Uveitis Secondary to Sarcoidosis From Idiopathic Disease. JAMA Ophthalmol. 2018, 136, 109-115. [CrossRef] [PubMed]

154. Dana, M.-R.; Merayo-Lloves, J.; Schaumberg, D.A.; Foster, C.S. Prognosticators for Visual Outcome in Sarcoid Uveitis. Ophthalmology 1996, 103, 1846-1853. [CrossRef]

155. Shaw, J.A.; Smit, D.; Griffith-Richards, S.; Koegelenberg, C.F.N. Utility of routine chest radiography in ocular tuberculosis and sarcoidosis. Int. J. Tuberc. Lung Dis. 2018, 22, 1374-1377. [CrossRef]

156. Rothova, A.; Groen, F. Ocular Involvement in Sarcoidosis. Semin. Respir. Crit. Care Med. 2017, 38, 514-522. [CrossRef]

157. Birnbaum, A.D.; Oh, F.S.; Chakrabarti, A.; Tessler, H.H.; Goldstein, D.A. Clinical Features and Diagnostic Evaluation of BiopsyProven Ocular Sarcoidosis. Arch. Ophthalmol. 2011, 129, 409-413. [CrossRef]

158. Takada, K.; Matsumoto, S.; Kojima, E.; Iwata, S.; Tanaka, K. Diagnostic management of patients with suspected ocular sarcoidosis. J. Thorac. Dis. 2013, 5, 135-140.

159. Chung, Y.-M.; Lin, Y.-C.; Liu, Y.-T.; Chung, Y.-M.; Liu, H.-N.; Hsu, W.-H. Uveitis with Biopsy-proven Sarcoidosis in Chinese-A Study of 60 Patients in a Uveitis Clinic Over a Period of 20 Years. J. Chin. Med. Assoc. 2007, 70, 492-496. [CrossRef]

160. Kaiser, P.K.; Lowder, C.Y.; Sullivan, P.; Sanislo, S.R.; Kosmorsky, G.S.; A Meziane, M.; Rice, T.W.; Smith, S.D.; Meisler, D.M. Chest computerized tomography in the evaluation of uveitis in elderly women. Am. J. Ophthalmol. 2002, 133, 499-505. [CrossRef] 
161. Febvay, C.; Kodjikian, L.; Maucort-Boulch, D.; Perard, L.; Iwaz, J.; Jamilloux, Y.; Broussolle, C.; Burillon, C.; Seve, P. Clinical features and diagnostic evaluation of 83 biopsy-proven sarcoid uveitis cases. Br. J. Ophthalmol. 2015, 99, 1372-1376. [CrossRef] [PubMed]

162. Clement, D.S.; Postma, G.; Rothova, A.; Grutters, J.C.; Prokop, M.; De Jong, P.A. Intraocular sarcoidosis: Association of clinical characteristics of uveitis with positive chest high-resolution computed tomography findings. Br. J. Ophthalmol. 2009, 94, 219-222. [CrossRef] [PubMed]

163. Rahmi, A.; Deshayes, E.; Maucort-Boulch, D.; Varron, L.; Grange, J.D.; Kodjikian, L.; Seve, P. Intraocular sarcoidosis: Association of clinical characteristics of uveitis with findings from18F-labelled fluorodeoxyglucose positron emission tomography. Br. J. Ophthalmol. 2011, 96, 99-103. [CrossRef]

164. Chauvelot, P.; Skanjeti, A.; Jamilloux, Y.; De Parisot, A.; Broussolle, C.; Denis, P.; Ramackers, J.M.; Giammarile, F.; Kodjikian, L.; Sève, P. 18F-fluorodeoxyglucose positron emission tomography is useful for the diagnosis of intraocular sarcoidosis in patients with a normal CT scan. Br. J. Ophthalmol. 2019, 103, 1650-1655. [CrossRef] [PubMed]

165. Bernard, C.; Kodjikian, L.; Bancel, B.; Isaac, S.; Broussolle, C.; Sève, P. Ocular sarcoidosis: When should labial salivary gland biopsy be performed? Graefes Arch. Clin. Exp. Ophthalmol. 2012, 251, 855-860. [CrossRef]

166. Hadjadj, J.; Dechartres, A.; Chapron, T.; Assala, M.; Salah, S.; Dunogué, B.; Musset, L.; Baudin, B.; Groh, M.; Blanche, P.; et al. Relevance of diagnostic investigations in patients with uveitis: Retrospective cohort study on 300 patients. Autoimmun. Rev. 2017, 16, 504-511. [CrossRef]

167. Takahashi, T.; Azuma, A.; Abe, S.; Kawanami, O.; Ohara, K.; Kudoh, S. Significance of lymphocytosis in bronchoalveolar lavage in suspected ocular sarcoidosis. Eur. Respir. J. 2001, 18, 515-521. [CrossRef]

168. Ohmichi, M. [Histologic diagnosis of sarcoidosis]. Nihon rinsho. Jpn. J. Clin. Med. 2002, 60, 1759-1765.

169. Ohara, K.; Okubo, A.; Kamata, K.; Sasaki, H.; Kobayashi, J.; Kitamura, S. Transbronchial Lung Biopsy in the Diagnosis of Suspected Ocular Sarcoidosis. Arch. Ophthalmol. 1993, 111, 642-644. [CrossRef]

170. De Boer, S.; Milne, D.G.; Zeng, I.; Wilsher, M.L. Does CT scanning predict the likelihood of a positive transbronchial biopsy in sarcoidosis? Thorax 2009, 64, 436-439. [CrossRef]

171. Mochizuki, M.; Smith, J.R.; Takase, H.; Kaburaki, T.; Acharya, N.R.; A Rao, N. Revised criteria of International Workshop on Ocular Sarcoidosis (IWOS) for the diagnosis of ocular sarcoidosis. Br. J. Ophthalmol. 2019, 103, 1418-1422. [CrossRef] [PubMed]

172. Takase, H.; Shimizu, K.; Yamada, Y.; Hanada, A.; Takahashi, H.; Mochizuki, M. Validation of international criteria for the diagnosis of ocular sarcoidosis proposed by the first international workshop on ocular sarcoidosis. Jpn. J. Ophthalmol. 2010, 54, 529-536. [CrossRef] [PubMed]

173. Acharya, N.R.; Browne, E.N.; Rao, N.; Mochizuki, M. Distinguishing Features of Ocular Sarcoidosis in an International Cohort of Uveitis Patients. Ophthalmology 2018, 125, 119-126. [CrossRef] [PubMed]

174. Handa-Miyauchi, M.; Takase, H.; Tanaka, M.; Akiyama, M.; Ohno-Matsui, K.; Mochizuki, M. A Validation Study of the Revised Diagnostic Criteria from the International Workshop on Ocular Sarcoidosis at a Single Institute in Japan. Ocul. Immunol. Inflamm. 2020, 1-6. [CrossRef]

175. Baughman, R.P.; E Lower, E.; Ingledue, R.; Kaufman, A.H. Management of ocular sarcoidosis. Sarcoidosis Vasc. Diffus. Lung Dis. Off. J. WASOG 2012, 29, 26-33.

176. Baughman, R.P.; E Lower, E.; A Bradley, D.; A Raymond, L.; Kaufman, A. Etanercept for Refractory Ocular Sarcoidosis. Chest 2005, 128, 1062-1067. [CrossRef]

177. Maneiro, J.R.; Salgado, E.; Gomez-Reino, J.J.; Carmona, L. Efficacy and Safety of TNF Antagonists in Sarcoidosis: Data from the Spanish Registry of Biologics BIOBADASER and a Systematic Review. Semin. Arthritis Rheum. 2012, 42, 89-103. [CrossRef]

178. El Jammal, T.; Jamilloux, Y.; Gerfaud-Valentin, M.; Valeyre, D.; Sève, P. Refractory Sarcoidosis: A Review. Ther. Clin. Risk Manag. 2020, 16, 323-345. [CrossRef]

179. Riancho-Zarrabeitia, L.; Calvo-Río, V.; Blanco, R.; Mesquida, M.; Adan, A.M.; Herreras, J.M.; Aparicio, Á.; Peiteado-Lopez, D.; Cordero-Coma, M.; Serrano, J.L.G.; et al. Anti-TNF- $\alpha$ therapy in refractory uveitis associated with sarcoidosis: Multicenter study of 17 patients. Semin. Arthritis Rheum. 2015, 45, 361-368. [CrossRef]

180. Erckens, R.J.; Mostard, R.L.M.; Wijnen, P.A.H.M.; Schouten, J.S.A.G.; Drent, M. Adalimumab successful in sarcoidosis patients with refractory chronic non-infectious uveitis. Graefes Arch. Clin. Exp. Ophthalmol. 2011, 250, 713-720. [CrossRef]

181. Marquet, A.; Chapelon-Abric, C.; Maucort-Boulch, D.; Cohen-Aubart, F.; Pérard, L.; Bouillet, L.; Abad, S.; Bielefeld, P.; Bouvry, D.; André, M.; et al. Efficacy and Safety of TNF Antagonists in Ocular Sarcoidosis: Data from the French Registry STAT. Sarcoidosis Vasc Diffus. Lung Dis. 2017, 34, 74.

182. Sève, P.; Kodjikian, L.; Adélaïde, L.; Jamilloux, Y. Uveitis in adults: What do rheumatologists need to know? Jt. Bone Spine 2015, 82, 308-314. [CrossRef] [PubMed]

183. Wartique, L.; Jamilloux, Y.; Bernecourt, A.D.P.D.; Kodjikian, L.; Ghesquieres, H.; Ide, C.; Sève, P. Development of Vitreoretinal Lymphoma in a Patient with Sarcoid Uveitis. Ocul. Immunol. Inflamm. 2019, 28, 647-650. [CrossRef] [PubMed]

184. Beccastrini, E.; Vannozzi, L.; Bacherini, D.; Squatrito, D.; Emmi, L. Successful Treatment of Ocular Sarcoidosis with Rituximab. Ocul. Immunol. Inflamm. 2013, 21, 244-246. [CrossRef]

185. Baughman, R.P.; Lower, E.E.; Kaufman, A.H. Rituximab for refractory granulomatous eye disease. Clin. Ophthalmol. 2012, 6, 1613. [CrossRef] 
186. Silpa-Archa, S.; Oray, M.; Preble, J.M.; Foster, C.S. Outcome of tocilizumab treatment in refractory ocular inflammatory diseases. Acta Ophthalmol. 2016, 94, e400-e406. [CrossRef]

187. Sejournet, L.; Kodjikian, L.; Grange, L.; Grumet, P.; Jamilloux, Y.; Sève, P. Resolution of ocular and mediastinal sarcoidosis after Janus kinase inhibitor therapy for concomitant rheumatoid arthritis. Clin. Exp. Rheumatol. 2020. online ahead of print.

188. Dave, N.; Chevour, P.; Mahendradas, P.; Venkatesh, A.; Kawali, A.; Shetty, R.; Ghosh, A.; Sethu, S. Increased Aqueous Humor CD4+/CD8+ Lymphocyte Ratio in Sarcoid Uveitis. Ocul. Immunol. Inflamm. 2019, 27, 1033-1040. [CrossRef]

189. Bonacini, M.; Soriano, A.; Cimino, L.; De Simone, L.; Bolletta, E.; Gozzi, F.; Muratore, F.; Nicastro, M.; Belloni, L.; Zerbini, A.; et al. Cytokine Profiling in Aqueous Humor Samples From Patients With Non-Infectious Uveitis Associated With Systemic Inflammatory Diseases. Front. Immunol. 2020, 11, 358. [CrossRef]

190. Carreño, E.; Portero, A.; Herreras, J.M.; García-Vázquez, C.; Whitcup, S.M.; Stern, M.E.; Calonge, M.; Enríquez-De-Salamanca, A. Cytokine and chemokine tear levels in patients with uveitis. Acta Ophthalmol. 2017, 95, e405-e414. [CrossRef]

191. Choi, R.Y.; Rivera-Grana, E.; Rosenbaum, J.T. Reclassifying Idiopathic Uveitis: Lessons From a Tertiary Uveitis Center. Am. J. Ophthalmol. 2019, 198, 193-199. [CrossRef] [PubMed] 